\title{
Effects of social value orientation (SVO) and decision mode on controlled information acquisition-A Mouselab perspective
}

\author{
Maik Bieleke ${ }^{1,2,3^{*}}$ David Dohmen ${ }^{3,4}$ Peter M. Gollwitzer ${ }^{5}$ \\ ${ }^{1}$ Department of Psychology, University of Konstanz, Germany \\ ${ }^{2}$ Department of Empirical Educational Research, University of Konstanz, Germany \\ ${ }^{3}$ Graduate School of Decision Sciences, University of Konstanz, Germany \\ ${ }^{4}$ Department of Economics, University of Konstanz, Germany \\ ${ }^{5}$ Department of Psychology, New York University, USA
}

\begin{tabular}{|l|}
\hline ACCEPTED MANUSCRIPT (Author Version) \\
Bieleke, M., Dohmen, D., \& Gollwitzer, P.M. (2020). Effects of social value orientation (SVO) and \\
decision mode on controlled information acquisition-A Mouselab perspective. Journal of \\
Experimental Social Psychology, 86. Advance online publication. doi: 10.1016/j.jesp.2019.103896
\end{tabular}

\author{
*Corresponding Author: \\ Maik Bieleke \\ P.O. Box 39 \\ University of Konstanz \\ 78457 Konstanz, Germany \\ Fon: ++49-(0)-7531-88 2635 \\ E-mail: maik.bieleke@uni-konstanz.de
}

\section{Acknowledgments:}

The authors gratefully acknowledge financial support by the German Research Foundation (DFG) through the research unit "Psychoeconomics" (FOR 1882). 


\begin{abstract}
Insights into the processes underlying observed decisions are crucial for a comprehensive understanding of behavior. We investigate how individual social value orientation (SVO) relates to controlled information acquisition and how this relationship may be governed by intuitive versus reflective decision modes. We measure controlled information acquisition with the process tracing tool Mouselab and demonstrate its potential for advancing research on social decision-making. In two experiments, participants worked on two consecutive SVO tasks, in which they allocated points between themselves and others. Information regarding the available distributions of points had to be actively acquired by moving the mouse cursor over corresponding boxes on the screen. We observed a stable relationship between SVO and controlled information acquisition in both experiments: less selfish participants acquired more information and made more other-oriented acquisitions, and this relationship showed up in both an intuitive and a reflective decision mode. However, participants in a reflective decision mode acquired more information, their acquisitions were more strongly other-oriented, and their decisions were more prosocial compared to participants in an intuitive mode. Taken together, our results advance research on SVO by showing that non-selfish individuals invest considerable time and effort to gauge the consequences of their decisions for others, which might underlie the pervasive effects of SVO on many socially relevant behaviors. Moreover, we demonstrate how intuitive versus reflective decision modes can alter controlled information acquisition. Finally, our results illustrate that Mouselab is a simple-to-use and versatile tool for tracing cognitive processes underlying social psychological phenomena.
\end{abstract}

Keywords: Mouselab; Process tracing; Social value orientation (SVO); Intuitive and reflective decision modes; Mental contrasting with implementation intentions (MCII) 


\section{Introduction}

Understanding the processes that lead to decisions is an important way of gaining insights into the reasons of observed behavior. Researchers today can resort to a wide variety of tools for assessing these processes, including cognitive modeling of decision times, self-reports, analyses of search patterns, as well as psychophysiological and neural measurements (for reviews, see Schulte-Mecklenbeck et al., 2017; Voss, Nagler, \& Lerche, 2013). However, the hurdles for using these process tracing tools can be quite high, ranging from specialized or expensive equipment and sophisticated experimental setups to complicated data analyses. A notable exception is Mouselab, a simple and easy-to-use process tracing tool that has originated from the literature on judgment and decision making (Payne, Bettman, \& Johnson, 1988, 1993). For instance, Mouselab has been useful for understanding how people make consumption decisions (Mitchell, Kahn, \& Knasko, 1995; Reisen, Hoffrage, \& Mast, 2008) or how they reason in strategic interactions (Costa-Gomes \& Crawford, 2006; Johnson, Camerer, Sen, \& Rymon, 2002). However, Mouselab has rarely been used for studying major topics in social psychology. For instance, a search of the Journal of Experimental Social Psychology archive reveals only one single hit for the term "Mouselab" — a short communication on eye-tracking that mentions Mouselab casually (Sütterlin, Brunner, \& Opwis, 2008). This is unfortunate because Mouselab is helpful for developing and testing models of human behavior (Schulte-Mecklenbeck, Kühberger, \& Ranyard, 2011). In the present research, we studied the potential of Mouselab as process tracing tool in social psychological research. Specifically, we investigated whether Mouselab reproduces key findings obtained with eye-tracking despite its considerably stronger reliance on controlled compared to automatic information acquisition, and the robustness of Mouselab results across intuitive and reflective decision modes. Beyond that, we scrutinized the direct 
effect of adopting intuitive versus reflective decision modes on information acquisition and social decision making.

In a typical Mouselab setting, information about a decision is not simply presented to participants (e.g., the payoff associated with choosing a certain option). Before making a decision, participants instead have to actively acquire the information they are interested in. This is usually achieved by "hiding" the available information behind boxes and instructing participants to move the mouse cursor over these boxes in order to temporarily uncover the corresponding information (Willemsen \& Johnson, 2011). As soon as participants remove the cursor from the box, the information is hidden again. The computer program merely has to record the points in time when a specific box is entered or left. This allows researchers to assess two important characteristics of controlled information acquisition: the scope of the acquisition (e.g., total duration, number of acquisitions) as well as the acquisition style (e.g., type of information acquired, transitions between boxes). Due to the effort Mouselab entails for acquiring information in terms of time and the necessity to actively move the cursor from box to box, it is particularly well-suited for assessing controlled information acquisition (as compared to more automatic acquisitions assessed by eye-tracking, for example; Glöckner \& Betsch, 2008; Norman \& Schulte-Mecklenbeck, 2010).

In our research, we used Mouselab to study how differences in distributional social preferences relate to controlled information acquisition. In social psychological research, these preferences are commonly captured by the concept of social value orientation (SVO; Balliet, Parks, \& Joireman, 2009; Messick \& McClintock, 1968; Murphy \& Ackermann, 2014). Specifically, SVO captures the preferences people have for allocating resources to themselves versus others. For instance, prosocial individuals try to maximize joint incomes or to minimize 
income differences, competitive individuals try to maximize their incomes relative to others, and selfish individuals attempt to maximize their incomes irrespective of others (Au \& Kwong, 2004). A large body of literature has examined differences in SVO and documented associations with several relevant aspects of everyday social behavior, such as pro-environmental attitudes (Gärling, Fujii, Gärling, \& Jakobsson, 2003; Sütterlin, Brunner, \& Siegrist, 2013), political ideology (Chirumbolo, Leone, \& Desimoni, 2016; van Lange, Bekkers, Chirumbolo, \& Leone, 2012), willingness to donate (Bekkers, 2007; van Lange, Bekkers, Schuyt, \& van Vugt, 2007), and interpersonal relations (van Lange, Agnew, Harinck, \& Steemers, 1997). Accordingly, differences in SVO are a potent determinant of interpersonal behavior, and investigating how these differences relate to controlled information acquisition is crucial for a better understanding of these behaviors (e.g., its stability across social contexts).

The present research therefore had two main objectives: In Experiment 1, we addressed the general usefulness of Mouselab as a tool for studying the association between SVO and controlled information acquisition. To this end, we adopted a task paradigm originally designed for examining the relationship between SVO and more automatic information acquisition measured by eye-tracking (Fiedler, Glöckner, Nicklisch, \& Dickert, 2013). Fiedler et al. (2013, Experiment 1) determined participants' social value orientation from a first SVO task and then examined its association with information acquisition in this first SVO task as well as a second SVO task. The authors reasoned that competitive decisions (i.e., maximize relative payoff) and prosocial decisions (i.e., maximize joint payoff or minimize payoff difference) require information about both the own and the other's payoff, whereas selfish decisions (i.e., maximize own payoff) merely require information about the own payoff. In line with this reasoning, competitive and prosocial individuals took more time to decide overall and acquired more 
information than selfish individuals. Moreover, they paid greater attention to the other's payoff and their acquisitions more often involved comparisons with the other's payoff.

Adopting this task paradigm had two major advantages: first, the two SVO tasks considerably varied in complexity (binary-choice options versus nine-choice options) and thus provided benchmarks for simple and complex social decision making that may very well relate to different scopes and styles of information acquisition. Second, the similarities between our Mouselab and the eye-tracking study allow for comparisons of these two process tracing tools. With eye tracking, all information is visible and participants can look directly from one piece of information to another. With Mouselab, on the other hand, information is hidden behind boxes and participants have to move the mouse over these boxes before they can see the corresponding information. These motor movements take more time than eye gazes, and a single information acquisition in Mouselab studies can therefore last up to five times longer than in eye tracking studies (Lohse \& Johnson, 1996). This prolongation of processing time tends to favor controlled information acquisitions in comparison to eye tracking, which is more conducive to the application of automatic acquisition styles (Glöckner \& Betsch, 2008; Glöckner \& Herbold, 2011). A comparison of these two tracing tools might thus yield qualitatively different findings.

In Experiment 2, we turned to our second major objective and investigated how the controlled information acquisition assessed by Mouselab changes when people adopt intuitive versus reflective decision modes. It is plausible that people approach social decision making tasks in different decision modes, for instance, depending on how motivated they are to think through their decisions (Choi, Koo, Choi, \& Auh, 2008). These differences in decision mode are especially likely to affect the scope of controlled information acquisition: reflective decisions should take more time and involve the acquisition of greater amounts of information than 
intuitive decisions (Rubinstein, 2007). Moreover, previous research has shown that the effects of

SVO on behavior can be moderated by decision modes, with SVO differences being more relevant for decision making in an intuitive than in a reflective mode. For instance, prosocial individuals make higher donations than selfish individuals when an intuitive rather than a reflective decision mode is encouraged by means of cognitive load (Cornelissen, Dewitte, \& Warlop, 2011). Similarly, prosocial individuals who planned to adopt an intuitive decision mode were more likely to reject unfair offers than those who planned to adopt a reflective decision mode (Bieleke, Gollwitzer, Oettingen, \& Fischbacher, 2017). In Experiment 2, we therefore experimentally induced intuitive versus reflective decision modes and tested their direct effects on information acquisition as well as whether they moderated the associations between SVO and information acquisition.

\section{Experiment 1: SVO and information acquisition}

In Experiment 1, we used Mouselab to study the association between SVO and controlled information acquisition. We adopted a task paradigm that was used in an experiment analyzing this association via eye-tracking data (Fiedler et al., 2013; Experiment 1). In this task paradigm, participants work on two consecutive SVO tasks, one involving simple choices between two available options and the other involving more complex choices between nine available options. Analogous to Fiedler et al. (2013), we determined participants' SVO in the first task and then examined its relation to information acquisition in both the first and the second task (i.e., withintask and between-task comparisons). This approach also allowed us to test whether Mouselab detects interindividual differences in controlled information acquisition in the SVO tasks, and to check how our results compare to those obtained in the Fiedler et al. (2013) study with eyetracking. In the following, we report all measures, manipulations and exclusions. 


\section{Participants}

We recruited 24 student participants $(81.8 \%$ female, age: $M=23.3$ years, $S D=4.0)$. The sample size was determined before any data analysis and is sufficient to detect medium effects with a power of $80 \%$ and an $\alpha$ error probability of $5 \%$ in two-tailed paired $t$-tests $\left(d_{z}=0.60\right.$; Faul, Erdfelder, Lang, \& Buchner, 2007). We expected to observe at least medium effects given that

Fiedler et al. (2013) reported substantial associations between SVO and information acquisition. As we were interested in an analysis of continuous SVO scores, these considerations did not take the random distribution of nominal SVO types into account. The experiment was programmed and conducted using z-Tree (Fischbacher, 2007) and PsychoPy (Peirce, 2007, 2009).

\section{Materials}

SVO tasks. Participants worked on two consecutive SVO tasks: first, the Ring Task (Liebrand, 1984; Liebrand \& McClintock, 1988) and then the Slider Task (Murphy, Ackermann, \& Handgraaf, 2011). In both tasks, they decided on the allocation of points between themselves and an anonymous other participant. The Ring Task comprised 24 items with two available options each, whereas the Slider Task consisted of 6 items with nine available options each (see Supplementary Information 1 for on overview of all items). The parameterization of the available options was based on a circle with its center at $(50,50)$ and a radius of 50 (see Murphy et al., 2011), and all possible values were therefore positive. A continuous SVO score was then computed from participants' decisions using the following formula (Murphy \& Ackermann, 2014):

$$
\text { SVO score }=\arctan \left(\frac{\sum\left(P_{\text {other }}-50\right)}{\sum\left(P_{\text {Self }}-50\right)}\right)
$$


in which $P_{\text {Self }}$ and $P_{\text {other }}$ denote the points allocated to oneself and to the other participant, respectively. A higher SVO score corresponds to more prosocial decisions in both tasks. ${ }^{1}$ Additionally, participants can be categorized into nominal types based on their SVO score (e.g., for plotting; Murphy \& Ackermann, 2014). The two most commonly observed SVO types are cooperative (i.e., maximizing joint payoffs or minimizing payoff differences) and individualistic (i.e., maximizing the own payoff). Besides, two less frequently observed SVO types are altruistic (i.e., maximizing the other's payoff) and competitive (i.e., maximizing the own payoff relative to the other's payoff). These categories are obtained by discretizing the continuous SVO scores into altruistic (Ring score: 67.5 to 112.5; Slider score: >57.15), cooperative (Ring score: 22.5 to 67.5; Slider score: 22.45 to 57.15 ), individualistic (Ring score: -22.5 to 22.5 ; Slider score: -12.04 to 22.45), and competitive (Ring score: -67.5 to -22.5 ; Slider score: $<-12.04$ ) value ranges. The Slider Task is limited to assessing these four types, whereas in the Ring Task additional types are possible but rarely observed (Au \& Kwong, 2004).

Mouselab design. Both the Ring Task and the Slider Task were presented in a Mouselab design (see Figure 1). Information about the available options was hidden behind boxes that were organized in a matrix-like manner. Boxes belonging to one option were connected by a line with a blue dot at the middle of it. Participants obtained information about a box by moving the mouse cursor over it. The corresponding points were then displayed until the cursor was removed from the box. Participants selected an option by clicking on the blue dot between the corresponding boxes. To prevent unwanted effects of information display on acquisition (e.g., reading from left to right), we fully counter-balanced the organization of the display (Norman \& SchulteMecklenbeck, 2010; Willemsen \& Johnson, 2011): the arrangement of allocations (horizontal vs. vertical), the order of options (i.e., running from left/top to right/bottom vs. from right/bottom to 
left/top), and the position of the own and the other's payoff information (left/top vs. right/bottom). This yielded a total of $2 \times 2 \times 2=8$ different conditions varied between participants such that all conditions occurred equally often in our data.

\section{Procedure}

At the beginning of the experiment, participants learned that they would work on two consecutive tasks. Afterwards, they received instructions for the Ring Task (see Fig. 1a and Supplementary Information 2). They proceeded with an example item (see Supplementary Information 3) that demonstrated the acquisition of information (i.e., moving the mouse over the boxes) and the way of making a decision (i.e., clicking the dot between two boxes). In the Ring Task, each of the 24 trials started with a screen showing a dot that participants had to click on. Immediately thereafter, the boxes appeared on the screen. Importantly, the dot was always positioned in the middle between the appearing four boxes, making sure that the mouse position was not initially biased (e.g., towards the own versus the other's payoff).

After the Ring Task, participants received instructions and an example item for the Slider Task (see Figure 1b and Supplementary Information 2 and 3). The procedure of the six Slider Task items was identical to the Ring Task except that the point participants had to click on prior to each trial was now positioned between the four boxes of two randomly selected adjacent allocations to prevent initial biases.

Participants always started with the Ring Task and then proceeded to the Slider Task. We used the order of items suggested by Murphy and colleagues (2011) and held it constant across participants. At the end of the experiment, participants chose between a flat payment of 5 Euros or course credit and additionally received a decision-compatible payoff irrespective of this choice. We determined this payoff with a ring matching protocol separately for each task (see 
Crosetto, Weisel, \& Winter, 2012, for details). First, for each participant one of the decisions made in the task was selected at random. Then, participants were randomly ordered and, based on the selected decisions, Participant 1 gave points to Participant 2, Participant 2 gave points to Participant $3, \ldots$, and Participant $N$ gave points to Participant 1 . Thus, participants once chose points for themselves and once received points from another participant. We added these points and converted them into Euros (100 points $=1$ Euro). The resulting average additional payoff was about 1 Euro for the Ring Task and 1.50 Euros for the Slider Task.

\section{Results and discussion}

SVO scores. The distributions of SVO scores in the Ring Task $(M=18.3, S D=19.4)$ and the Slider Task $(M=22.5, S D=14.0)$ are depicted in Figure 2. In the Ring Task, 16 participants were classified as individualists and 8 as cooperators. In the Slider Task, 12 participants were classified as individualists and 12 as cooperators (see also Supplementary Information 6). Similar differences in nominal classifications between Ring Task and Slider Task have been observed in previous literature as well (Murphy et al., 2011). Moreover, there was a substantial correlation between the SVO scores derived from the two tasks, $r=.80, t(22)=6.20, p<.001$, which is somewhat larger than observed in previous research (e.g., $r=.66$ in Fiedler et al., 2013; $r=.65$ in Murphy et al., 2011). A reason might be that our sample size was too small to accurately estimate the correlation (Schönbrodt \& Perugini, 2013). This notwithstanding, the finding suggests that Mouselab does not distort the SVO measurement (e.g., due to a reduced number of prosocial individuals resulting from increased costs of acquiring information about the other's payoff).

Information acquisition. We computed the same five indices of information acquisition used in the eye-tracking study of Fiedler et al. (2013), adapted to Mouselab: how long it took 
participants to make their decision (decision time) ${ }^{2}$ how often they acquired information about boxes (total number of acquisitions), the number of unique boxes they acquired information from (number of unique acquisitions), what proportion of the acquired information was related to the other's payoff (\% acquisitions of other's payoff), and an index for whether participants preferred comparisons of payoffs involving the other versus comparisons among only their own payoffs (transition index; for more details, see Fiedler et al., 2013). ${ }^{3}$ Prior to determining these indices, we removed very brief acquisitions of $\leq 200 \mathrm{~ms}$, which likely reflect inadvertent mouse movements rather than controlled acquisitions. In line with recommendations in the literature (Willemsen \& Johnson, 2011) and with Fiedler et al. (2013), we log-transformed decision time, total number of acquisitions, and number of unique acquisitions for the statistical analysis using the natural logarithm.

Ring task. We first computed the five indices of information acquisition in the Ring Task and regressed each of them on the absolute SVO score determined from the Ring Task decisions (i.e., within-task predictions). We used the absolute SVO score because higher values reflect stronger deviations from a perfectly selfish score of 0 in both the competitive direction (i.e., $<0$ ) and the prosocial direction (i.e., > 0), as suggested by Fiedler et al. (2013). Mirroring these authors' results, the absolute SVO score emerged as a positive predictor of all five indices (Table 1 and Figure 3): Participants who deviated more strongly from a perfectly individualistic SVO score spent more time on making their decisions, $b=0.010, S E=0.004, p=.004$, acquired (marginally) more information in total, $b=0.005, S E=0.003, p=.079$, as well as more unique information, $b=0.004, S E=0.001, p=.008$, paid more attention to information about the other's payoff, $b=0.297, S E=0.122, p=.015$, and were more strongly inclined to make comparisons involving the other's payoff, $b=0.016, S E=0.005, p=.001$. This suggests that Mouselab 
captures individual differences in controlled information acquisition in a simple two-choice decision making task.

Slider task. In the next step, we computed the five indices of information acquisition for the Slider Task and regressed them on the absolute SVO score determined from the Ring Task decisions (i.e., between-task predictions). We again found that the absolute SVO score positively predicted all five indices (Table 1 and Figure 3): Stronger deviations from a perfectly individualistic SVO score in the Ring Task predicted longer decision times, $b=0.013, S E=$ $0.004, p=.003$, more information acquisition in total, $b=0.009, S E=0.003, p=.001$, more acquisition of unique information, $b=0.005, S E=0.002, p=.038$, greater attention to the other's payoff, $b=0.339, S E=0.721, p=.004$, and more comparisons involving the other's payoff, $b=$ $0.014, S E=0.005, p=.008$. This suggests that Mouselab captures individual differences in controlled information acquisition also in a complex decision making task with nine available options, and the findings paralleled those obtained in the simpler Ring Task. Taken together, the results of Experiment 1 show a robust association between SVO and controlled information acquisition that mirrored those obtained in a study using eye-tracking to investigate information acquisition (Fiedler et al., 2013, Experiment 1). Specifically, we found that less selfish individuals have a greater acquisition scope and a more strongly other-oriented acquisition style. Thus, SVO does not only relate to automatic but also to controlled aspects of information acquisition. Moreover, our results suggest that Mouselab is a useful complement to other process tracing tools (e.g., eye-tracking) for studying information acquisition in social decision making.

\section{Experiment 2: information acquisition in intuitive vs. reflective decision modes}

In Experiment 2, we investigated how controlled information acquisition assessed by Mouselab changes as a consequence of inducing different decision modes, with a particular focus 
on whether these modes moderate the association between SVO and information acquisition as observed in Experiment 1. We again measured participants' social value orientation in the first SVO task. Before they proceeded to the second SVO task, however, we instructed them to make plans to approach the decisions either intuitively (intuitive condition) or reflectively (reflective condition). Participants in a control condition made no such plans and instead worked on a filler task. Establishing intuitive versus reflective decision modes in between the two consecutive SVO tasks allowed us to investigate the causal effects of these modes on information acquisition in the second task, and to inspect potential interactions between the decision modes and the SVO score measured in the first task. In the following, we report all measures, manipulations and exclusions.

\section{Participants}

We recruited 120 student participants $(62.5 \%$ female, age: $M=24.1$ years, $S D=5.5)$ and randomly assigned them to an intuitive, a reflective, or a control condition (40 participants per condition). Analogous to Experiment 1, sample size was determined before any data analysis and is sufficient to detect medium effects when comparing the three decision mode conditions with a power of $80 \%$ and an $\alpha$ error probability of $5 \%$ in a one-factorial ANOVA $(f=0.29$; Faul et al., 2007).

\section{Materials}

As in Experiment 1, participants always worked on the Ring Task first and then proceeded to the Slider Task. However, before they started with the Slider Task, participants in the intuitive and the reflective condition, respectively, planned to approach the decision in an intuitive or a reflective manner. Participants in the control condition worked on a neutral filler task. At the end of the experiment, we also added a final questionnaire. 
Intuitive and reflective plans. After having completed the Ring Task and before starting with the Slider Task, participants worked for 15 min on different paper-and pencil materials depending on which condition they were assigned to. Participants in the control condition worked on a simple letter-searching task that was neither incentivized nor related to the SVO tasks. In contrast, participants in the intuitive and the reflective condition received materials that guided them towards making intuitive and reflective plans, respectively (see Supplementary Information 4). They first specified their most important wish for the upcoming decisions to be made, and then imagined the best outcome associated with realizing this wish. In the reflective condition, participants were then instructed to consider acting in a hasty way as a potential obstacle for realizing their wish and made plans specifying how to overcome this obstacle: "If I start acting in a hasty way, then I will tell myself: Use your brain!" In the intuitive condition, in contrast, participants were asked to consider pondering at length as a potential obstacle and to make a respective plan: "If I start pondering at length, then I will tell myself: Listen to your guts!" This procedure is a combination of mental contrasting (MC; Oettingen, 2012; Oettingen, Pak, \& Schnetter, 2001) and implementation intentions (II; Gollwitzer, 1999, 2014) that is called MCII (Oettingen, 2014) and has been used to induce behavior change in the health, achievement, and interpersonal domains. Importantly, it has also been successfully used to encourage participants to adopt intuitive versus reflective decision modes (Bieleke et al., 2017; Dohmen, Gollwitzer, Fischbacher, \& Oettingen, 2019; Martiny-Huenger, Bieleke, Oettingen, \& Gollwitzer, 2017). The key idea is that engaging participants in the intuitive and reflective MCII helps them to recognize the respective obstacles of pondering at length or acting in a hasty way, and to overcome these obstacles by adopting a corresponding decision mode (i.e., being intuitive instead of pondering at length and being reflective instead of acting hastily). 
Final questionnaire. At the end of the experiment, participants completed a final questionnaire (see Supplementary Information 5) with demographic questions (i.e., age, gender, first language, major and minor field of study, current semester, number of mathematics and statistics courses attended) as well as items to check whether participants understood the manipulation instructions and to test whether critical prerequisites for the intuitive and the reflective plans were met: participants must be committed to the plans and the plans have to be both generally relevant (i.e., specify obstacles that participants generally encounter) and relevant in the specific context (i.e., provide a strategy to effectively deal with the obstacle). All questions had to be answered on Likert scales ranging from 1 (does not apply) to 7 (does fully apply).

Comprehension check. We presented three pairs of items asking whether participants felt required to respond slowly, to think carefully, and to make good decisions. Half of the items were phrased in terms of reflective decision making (e.g., "I felt instructed to make my decisions slowly"). The other half was phrased in terms of intuitive decision making (e.g., "I felt instructed to make my decisions quickly") and we reverse-coded participants' answers to these items. We then averaged answers to all six items into a single composite score (Cronbach's $\alpha=.72)$, which reflected the degree to which participants felt required to engage in reflective rather than intuitive decision making.

Prerequisites for plan effectiveness. For the plans to effectively induce intuitive versus reflective decision modes, participants had to be committed to act upon them and the plans had to be relevant in general as well as in our specific study. We assessed plan commitment with a set of four items (e.g., "I was strongly committed to the plan", "Frankly, I didn't care if I acted upon the plan or not") that has been validated for research purposes (Klein, Wesson, Hollenbeck, Wright, \& DeShon, 2001), coded all answers towards higher commitment, and averaged them 
into a single score (Cronbach's $\alpha=.76$ ). General plan relevance refers to whether the plans specified an obstacle that participants generally encounter and that they perceive as hindering their decision making. We assessed this with two items asking whether participants in the intuitive and reflective condition, respectively, in general experienced pondering at length or acting hastily when making decisions ("In general, I ponder at length [act hastily] when making decisions") and whether doing so hindered their goal attainment ("In general, pondering at length [acting hastily] when making decisions prevents me from attaining my goals"). We collapsed the corresponding answers into a general plan relevance score (Cronbach's $\alpha=.71)$ that reflects whether the provided plan described an obstacle of general relevance for participants. Finally, we measured specific plan relevance, which refers to whether the plan helped participants prevent and deal with the corresponding obstacle in the specific decision context of our experiment. To this end, we asked participants in the intuitive and the reflective condition, respectively, whether they experienced pondering at length or acting hastily in this study ("In this study, I pondered at length [acted hastily] when making decisions"), whether doing so hindered their goal attainment ("In this study, pondering at length [acting hastily] when making decisions prevented me from attaining my goals"), and whether pondering at length and acting hastily were perceived as obstacles ("In this study, I perceived pondering at length [acting hastily] when making decisions as a possible obstacle to attaining my goals"). We collapsed the corresponding answers into a specific plan relevance score (Cronbach's $\alpha=.62$ ) that reflects whether the provided plan provided a relevant strategy that participants could use to deal with the specified obstacle.

\section{Results and discussion}

Comprehension check. Participants in the reflective condition perceived their plan as requiring them to make slower, more thoughtful, and better decisions than participants in the 
intuitive condition (reflective condition: $M=5.5, S D=1.1$; intuitive condition: $M=4.3, S D=$ 1.6), $t(78)=3.90, p<.001, d=0.87,95 \% \mathrm{CI}=[0.41,1.34]$. This is in line with our expectations and suggests that the intuitive and reflective plans successfully induced the corresponding decision mode.

\section{Prerequisites for plan effectiveness.}

Plan commitment. Commitment to the plan was strong in both the intuitive $(M=4.7, S D$ $=1.4)$ and the reflective condition $(M=4.0, S D=1.5)$, though commitment turned out to be stronger in the intuitive condition, $t(78)=2.12, p=.037, d=0.47,95 \% \mathrm{CI}=[0.02,0.92]$.

General plan relevance. One reason for the observed difference in plan commitment might be a difference in general plan relevance that we observed. Specifically, participants in the intuitive condition reported to be generally more inclined to ponder about decisions $(M=4.3, S D$ $=1.5)$ than reflective participants reported to act hastily $(M=2.8, S D=1.4), t(78)=4.64, p<$ $.001, d=1.04,95 \% \mathrm{CI}=[0.56,1.514]$. This might have rendered the obstacle specified in the intuitive plan more relevant than the one in the reflective plan.

Specific plan relevance. No significant difference between conditions emerged for specific plan relevance (intuitive condition: $M=2.7, S D=1.2$; reflective condition: $M=2.6, S D$ $=1.3), t(78)=0.46, p=.647, d=0.10,95 \% \mathrm{CI}=[-0.34,0.55]$, suggesting that the provided strategies were similarly relevant in both conditions.

Taken together, these results suggest that the prerequisites for plan effectiveness were met in both conditions. Yet, acting hastily was not perceived as much as a relevant obstacle as pondering at length and commitment to the reflective plan was less pronounced than commitment to the intuitive plans. We took this pattern of findings into account when evaluating the direct effects of plans on controlled information acquisition (see below). 
SVO distribution. The distributions of SVO scores in the Ring Task $(M=14.4, S D=$ 29.6) and the Slider Task $(M=24.3, S D=16.3)$ are depicted in Figure 4. In the Ring Task, nine participants were classified as competitive, 66 as individualistic, 40 as cooperative, three as altruistic, and two as sadistic (i.e., minimizing the other's payoff). In the Slider Task, one participant was classified as competitive, 54 as individualistic, 64 as cooperative, and one as altruistic (see also Supplementary Information 6). As in Experiment 1, scores from both tasks were positively correlated, $r=.55, t(118)=7.19, p<.001$. The lower correlation compared to Experiment 1 does not reflect violations of transitivity that might result, for instance, from an increase in random choices in our experimental conditions: only 4 out of 120 participants revealed intransitive preferences ( 2 in the intuitive, 1 in the control, and 1 in the reflective condition, $\chi^{2}(2)=0.52, p=.772$ ). However, the manipulation of decision modes might have weakened the correlation between SVO scores from the Ring Task and the Slider Task. Consistent with this interpretation, the correlation was .69 in the control condition versus .46 in the intuitive and .53 in the reflective condition.

Information acquisition. For the sake of consistency with the analysis of Experiment 1, we first examined the association between SVO and each of the five indicators of controlled information acquisition in the Ring Task and the Slider Task. We then tested whether these associations were moderated by decision modes in the Slider Task (i.e., in the task following the mode manipulation). Next, we turned to the direct influence of intuitive and reflective decision modes on information acquisition in the Slider Task, also taking into account the observed heterogeneity among participants in the prerequisites for plan effectiveness (i.e., commitment, relevance, and adequacy). Finally, we examined whether the assignment to different decision mode conditions affected choice behavior in the Slider Task by testing whether these modes 
predicted the SVO score in the Slider Task.

Social value orientation. Confirming the results of Experiment 1, the absolute SVO scores from the Ring Task predicted information acquisition in both the Ring Task (i.e., withintask prediction) and the Slider Task (i.e., between-task prediction), all $p$ s $<.001$ (see Table 2 for details): The more the absolute SVO score deviated from 0 , the more time participants spent on making their decisions and on acquiring (unique) information, the more they paid attention to information about the other's payoff, and the more their comparisons involved the other's payoff. ${ }^{4}$ Adding interaction effects of absolute SVO score and decision mode had negligible effects: In one model adjusted $R^{2}$ slightly increased because the absolute SVO score was a stronger predictor of the total number of acquisition in the reflective compared to the control condition, $b=0.005, S E=0.002, p=.042$. In the other models, adjusted $R^{2}$ did not change and even dropped when the interaction effects were added. This suggests that the associations between SVO and controlled information acquisition assessed by Mouselab are robust to differences in decision mode.

Decision modes. To investigate the direct effects of different decision modes on controlled information acquisition, we first regressed the five indicators on the intuitive versus reflective condition (Table 3). Although participants in the reflective condition had consistently larger values than participants in the intuitive condition on all indices of information acquisition, only the difference in the percentage of information acquired was significant at the $10 \%$ level, $b$ $=5.461, S E=3.002, p=.069$. However, when we accounted for the observed differences between conditions regarding the prerequisites of plan effectiveness (i.e., commitment, general plan relevance, and specific plan relevance), a more consistent picture emerged. Compared to intuitive participants, participants in the reflective condition took more time to decide, $b=0.205$, 
$S E=0.095, p=.031$, acquired more information in total, $b=0.200, S E=0.100, p=.046$, and more unique information, $b=0.182, S E=0.086, p=.034$. Moreover, they paid greater attention to the other's payoff, $b=9.961, S E=3.059, p=.001$, and had a stronger preference for comparisons involving the other's payoff, $b=0.341, S E=0.113, p=.003$.

To examine whether these changes in controlled information acquisition were accompanied by changes in participants' choices, we regressed the original SVO scores in the Slider Task on decision mode (i.e., intuitive versus reflective plan condition). This revealed a significant difference between conditions, as reflective participants had a higher SVO score than intuitive participants, $b=8.105, S E=3.535, p=.024$. This effect was more pronounced after accounting for heterogeneity in the prerequisites of plan effectiveness, $b=10.144, S E=3.995, p$ $=.013$. Taken together, these results suggest that decision modes affected information acquisition when taking the observed heterogeneity in the prerequisites of plan effectiveness into account. Specifically, participants in a reflective decision mode took more time to decide, acquired more (unique) information, and made more other-oriented comparisons than participants in an intuitive decision mode. This change in controlled information acquisition was accompanied by more prosocial SVO scores in the reflective compared to the intuitive condition. Nevertheless, the relationship between SVO and information acquisition proved robust to intuitive and reflective decision modes.

\section{General Discussion}

We used Mouselab (Payne et al., 1988, 1993) as an experimental tool for investigating controlled information acquisition in social decision making. In Experiment 1, Mouselab revealed SVO as predictor of information acquisition: The more participants deviated from a perfectly selfish SVO score, the more time it took them to decide, the more (unique) information 
they acquired, the more attention they paid to the other's payoff, and the stronger they preferred comparisons involving the other's payoff. These findings conceptually replicated the results of an eye-tracking study uncovering the association between SVO and information acquisition (Fiedler et al., 2013). However, our results go beyond a pure replication because Mouselab entails considerably higher acquisition costs than eye-tracking (Glöckner \& Betsch, 2008; Norman \& Schulte-Mecklenbeck, 2010). Accordingly, SVO seems to be an important determinant not only of automatic but also of more controlled information acquisition. For instance, prosocial individuals paid more attention to the consequences of their decisions for others than selfish individuals, although this required considerable time and effort.

Experiment 2 further confirmed the value of Mouselab for studying social decision making. SVO was associated with information acquisition in the same way as in Experiment 1, irrespective of whether participants adopted an intuitive or a reflective decision mode. Despite this robustness, however, information acquisition and decision making were influenced by these modes. Reflective participants decided in a more prosocial manner than intuitive participants and this effect was accompanied by corresponding changes in their controlled information acquisition. Compared to intuitive participants, reflective participants had a greater scope of information acquisition (i.e., more time, more acquisitions) and also displayed different styles of acquisition (i.e., greater attention to and comparisons involving the other's payoff).

\section{Implications for Research on Process Tracing Tools}

Our results suggest Mouselab as a valuable and simple-to-use tool for studying information acquisition in social psychological research. In contrast to the times when it was first introduced as a process tracing tool (e.g., Payne \& Braunstein, 1978), researchers today can choose between various tools for tracing cognitive and affective processes (Schulte-Mecklenbeck 
et al., 2017). Each tool comes with unique advantages and disadvantages and the research question at hand will determine which tool is most adequate. With regard to Mouselab, suitable questions primarily revolve around the characteristics of controlled information acquisition (Glöckner \& Betsch, 2008; Norman \& Schulte-Mecklenbeck, 2010). For example, in the present research we used Mouselab to investigate whether SVO is associated with controlled information acquisition, thereby adding to a literature that has so far focused more on subtle and automatic SVO effects (e.g., Chen \& Fischbacher, 2016; Fiedler et al., 2013).

A particular advantage of Mouselab is its minimal demand on equipment and programming, which makes it easy to adapt to established social psychological task paradigms (such as SVO in the present research) and to implement it in lab experiments. But it can also be used in online experiments (Willemsen \& Johnson, 2008), which become increasingly popular in social psychology (Gosling \& Mason, 2015; Kraut et al., 2004) given that online interactions between people are meanwhile easy to realize (Balietti, 2017; Chen, Schonger, \& Wickens, 2016). As motivation is an important issue for assuring validity especially in online experiments (Kaufmann, Schulze, \& Veit, 2011), a further advantage of Mouselab is its observed robustness to whether participants adopt intuitive or reflective decision modes (i.e., the association between SVO and information acquisition did not differ between these modes).

Finally, Mouselab can also be fruitfully combined with other process tracing tools to investigate whether a particular finding is robust across these tools (Schulte-Mecklenbeck et al., 2011). In the present research, we converted an eye-tracking study (Fiedler et al., 2013) into a Mouselab study and conceptually replicated the finding that SVO predicts information acquisition. Had we failed to replicate this finding, we might have concluded that SVO determines intuitive but not necessarily deliberate forms of information acquisition. As it turned 
out, however, SVO was an important determinant of the controlled information acquisition assessed by Mouselab. This result demonstrates the usefulness of Mouselab for a multi-method approach to studying decision making. Moreover, Mouselab can be directly combined with other process tracing tools (e.g., active information search and verbal protocols; Reisen et al., 2008), used to complement indirect measures of cognitive processes (e.g., decision time modeling; Bieleke, Dohmen, \& Gollwitzer, 2019), or modified to capture not only the acquisition but also the organization of information (Ettin, Bröder, \& Henninger, 2015). Therefore, Mouselab provides a flexible starting point for investigating information processing phenomena in social psychology.

\section{Implications for Research on Social Value Orientation}

Our research contributes to research on the cognitive processes that are assumed to underlie SVO (e.g., based on interdependence theory; Kelley \& Thibaut, 1978; see also McClintock \& Liebrand, 1988). So far, it seemed that SVO operates on a rather automatic level, primarily affecting behavior when people make intuitive rather than reflective decisions (Cornelissen et al., 2011). For instance, prosocial individuals become similarly likely as selfish individuals to accept unfair offers when they decide reflectively but not when they decide intuitively (Bieleke et al., 2017), and they contribute more to a public good when making fast rather than slow decisions (Mischkowski \& Glöckner, 2016). In line with these observations, studies using process tracing tools that capture processes in a less obvious and more natural way (e.g., eye-tracking), which allows for uncovering more automatic processing, have revealed SVO as a determinant of information acquisition and behavior (Chen \& Fischbacher, 2016; Fiedler et al., 2013). Our study extends these findings by showing that SVO also relates to more controlled information acquisition as captured by Mouselab. 
The evidence for relations between SVO and both automatic and controlled forms of information acquisition may also provide an explanation for why SVO is consistently shown to predict behaviors in a variety of social contexts (Balliet et al., 2009; Bogaert, Boone, \& Declerck, 2008). Research on simple perceptual and consumer choice suggests that the allocation of attention might be an important determinant of preferences (Krajbich, Armel, \& Rangel, 2010; Shimojo, Simion, Shimojo, \& Scheier, 2003; Towal, Mormann, \& Koch, 2013). For instance, when people are shown pictures of commercial products between which they have to choose, the product that receives greater attention on average is more likely to be chosen (Krajbich, Lu, Camerer, \& Rangel, 2012). A similar mechanism might underlie the association between SVO, information acquisition, and decision making. Individuals with higher absolute SVO scores in our experiments were mostly prosocial individuals (and also some competitive individuals in Experiment 2) who paid greater attention to the other's payoff and made more other-oriented comparisons. Accordingly, prosocial individuals might have decided in a more prosocial manner than selfish individuals partly because they attended more to information about the consequences of their decisions for others. The results of our Experiment 2 are consistent with this reasoning: reflective participants paid more attention to the other's payoff and made more other-oriented comparisons than intuitive participants, and they made more prosocial decisions as well. A further tentative conclusion from these results is that inducing reflective decision modes might be a viable strategy to foster prosocial decision making in other socially relevant contexts.

This argument also has implications for the current debate about whether intuitive or reflective decision modes promote prosocial behavior (e.g., Evans, Dillon, \& Rand, 2015; Krajbich, Bartling, Hare, \& Fehr, 2015). While the literature suggests that intuition underlies cooperative behavior in serval contexts (e.g., Rand, 2016), findings regarding dictator games (of 
which the SVO tasks consist) are mixed and often even suggest reflection rather than intuition as determinant of prosocial giving (Halsson, Siebner, \& Hulme, 2018). This latter observation is in line with our data, as we observed more prosocial decisions in the reflective than in the intuitive condition in Experiment 2. One explanation for conflicting results in the literature might pertain to how intuitive versus reflective decision modes affect information acquisition. Reflective participants in Experiment 2 paid greater attention to information about the other's payoff than intuitive participants and also displayed more prosocial SVO scores. Depending on the experimental setup, however, instructions to be reflective could direct participants' attention to other pieces of information as well. If, for instance, attention in a reflective condition is more strongly directed towards information about own payoffs, then this could promote selfish rather than prosocial decision making.

\section{Limitations and Outlook}

The direct effects of intuitive and reflective decision modes on controlled information acquisition in Experiment 2 were rather subtle and showed up especially when accounting for the differences in plan effectiveness (i.e., commitment, general plan relevance, and specific plan relevance) that emerged between conditions. This might be due to the specific manipulation we used for inducing these two decision modes. While instructing people to plan intuitive versus reflective decision modes has been repeatedly and successfully used in previous research (Bieleke et al., 2017; Dohmen et al., 2019; Martiny-Huenger et al., 2017), manipulations such as time pressure (Rand, Greene, \& Nowak, 2012) or cognitive load (Schulz, Fischbacher, Thöni, \& Utikal, 2014) might influence controlled information acquisition more strongly. In line with this argument, it has been shown that time pressure can alter information acquisition in Mouselab studies (Payne et al., 1988; Rieskamp \& Hoffrage, 1999). Unfortunately, however, these methods 
have the disadvantage that they cannot easily establish reflective decision modes, as the mere presence of time or the absence of load is difficult to equate with reflective decision making. Still, it would be interesting to set up our experiment with a time pressure or cognitive load manipulation to explore the robustness of our findings across methods. This would also be a valuable contribution because variations in decision mode due to differences in the willingness to think about a decision are likely to be similarly relevant in social decision making as variations resulting from restrictions of available (time or cognitive) resources.

It is, however, also possible that stronger decision mode manipulations might have obscured the association between SVO and information acquisition observed in our experiments. As an extreme example, in a study by Hochman, Ayal, and Ariely (2015, Exp. 3) participants had to choose between inspecting information either about their own payoffs or about the other's payoff, but it was not possible to inspect both. In this case, participants preferred to inspect information about their own payoff. Accordingly, escalating the costs of acquiring information by severe time limits or extreme cognitive load might eventually eliminate the differences in information acquisition associated with SVO.

When contemplating the use of Mouselab one should bear in mind that it creates a particular decision context that fosters controlled forms of information search and promotes the use of reflective strategies (Normann \& Schulte-Mecklenbeck, 2010). This resembles everyday decisions in which information is not readily available and must be actively acquired instead (e.g., when searching or asking for information). If, however, the research focus is primarily on more automatic forms of information acquisition, methods like eye-tracking (Fiedler et al., 2013) or the analysis of unintentionally left behind behavioral traces like click positions and decision times (Chen \& Fischbacher, 2016) might be more suitable approaches. This is also the case 
when, for instance, researchers want to avoid that participants' selection of decision strategies is affected by the additional memory demands Mouselab creates compared to methods like eyetracking (although research suggests that these differences might be small; Reisen et al., 2008).

Finally, there are several possible extensions of our work in future research. First, the Slider Task comprises a set of secondary items that distinguish between prosocial individuals with a motivation to maximize joint incomes versus the motivation to minimize income differences (Murphy et al., 2011). Using these items would allow to investigate potential information acquisition differences within prosocial individuals. Second, Mouselab can also be used to investigate controlled information acquisition in strategic social interactions (e.g., Camerer, Johnson, Rymon, \& Sen, 1993; Costa-Gomes et al., 2003; Johnson et al., 2002). As SVO and decision modes are both relevant in these contexts as well (e.g., Bieleke et al., 2017), future research might want to investigate the processes underlying SVO effects in strategic interactions and the consequences of engaging in intuitive versus reflective decision modes using Mouselab. 


\section{References}

Au, W. T., \& Kwong, J. Y. Y. (2004). Measurements and effects of social-value orientation in social dilemmas: A review. In R. Suleiman, D. V. Budescu, I. Fischer, \& D. M. Messick (Eds.), Contemporary psychological research on social dilemmas (pp. 71-98). New York: Cambridge University Press.

Balietti, S. (2017). nodeGame: Real-time, synchronous, online experiments in the browser. Behavior Research Methods, 49, 1696-1715. doi: 10.3758/s13428-016-0824-Z

Balliet, D., Parks, C., \& Joireman, J. (2009). Social value orientation and cooperation in social dilemmas: A meta-analysis. Group Processes \& Intergroup Relations, 12, 533-547. doi: $10.1177 / 1368430209105040$

Bekkers, R. (2007). Measuring altruistic behavior in surveys: The all-or-nothing dictator game. Survey Research Methods, 1, 139-144.

Bieleke, M., Dohmen, D., \& Gollwitzer, P. M. (2019). It's about time. How do intuition, strength of preferences, cognitive effort, and swiftness conjointly determine decision times?

(Manuscript submitted for publication).

Bieleke, M., Gollwitzer, P. M., Oettingen, G., \& Fischbacher, U. (2017). Social value orientation moderates the effects of intuition versus reflection on responses to unfair ultimatum offers. Journal of Behavioral Decision Making, 30, 569-581. doi: 10.1002/bdm.1975

Bogaert, S., Boone, C., \& Declerck, C. (2008). Social value orientation and cooperation in social dilemmas: A review and conceptual model. British Journal of Social Psychology, 47, 453480. doi: 10.1348/014466607X244970

Camerer, C., Johnson, E. J., Rymon, T., \& Sen, S. (1993). Cognition and framing in sequential bargaining for gains and losses. In K. Binmore, A. Kirman, \& P. Tani (Eds.), Frontiers of game theory (pp. 27-47). Cambridge, MA: MIT Press.

Chen, D. L., Schonger, M., \& Wickens, C. (2016). oTree-An open-source platform for laboratory, online, and field experiments. Journal of Behavioral and Experimental Finance, 9, 88-97. doi: 10.1016/j.jbef.2015.12.001

Chen, F., \& Fischbacher, U. (2016). Response time and click position: Cheap indicators of preferences. Journal of the Economic Science Association, 2, 109-126. doi: 10.1007/s40881016-0026-6

Chirumbolo, A., Leone, L., \& Desimoni, M. (2016). The interpersonal roots of politics: Social value orientation, socio-political attitudes and prejudice. Personality and Individual Differences, 91, 144-153. doi: 10.1016/j.paid.2015.12.001

Choi, J. A., Koo, M., Choi, I., \& Auh, S. (2008). Need for cognitive closure and information search strategy. Psychology and Marketing, 25, 1027-1042. doi: 10.1002/mar.20253

Cornelissen, G., Dewitte, S., \& Warlop, L. (2011). Are social value orientations expressed automatically? Decision making in the dictator game. Personality \& Social Psychology Bulletin, 37, 1080-1090. doi: 10.1177/0146167211405996

Costa-Gomes, M. A., \& Crawford, V. P. (2006). Cognition and behavior in two-person guessing games: An experimental study. American Economic Review, 96, 1737-1768. 
Costa-Gomes, M. A., Crawford, V. P., \& Broseta, B. (2003). Cognition and behavior in normalform games: An experimental study. Econometrica, 69, 1193-1235. doi:10.1111/14680262.00239.

Crosetto, P., Weisel, O., \& Winter, F. (2012). A flexible z-Tree implementation of the Social Value Orientation Slider Measure (Murphy et al. 2011)-Manual (Jena Economic Research Papers No. 2012-62). Retrieved from http://pubdb.wiwi.uni-jena.de/pdf/wp_2012_062.pdf

Dohmen, D., Gollwitzer, P. M., Fischbacher, U., \& Oettingen, G. (2019). Use your brains! How analytical thinking improves strategic sophistication. (Working paper).

Ettlin, F., Bröder, A., \& Henninger, M. (2015). A new task format for investigating information search and organization in multiattribute decisions. Behavior Research Methods, 47, 506-518. doi: 10.3758/s13428-014-0482-y

Evans, A. M., Dillon, K. D., \& Rand, D. G. (2015). Fast but not intuitive, slow but not reflective: Decision conflict drives reaction times in social dilemmas. Journal of Experimental Psychology: General, 144, 951-966. https://doi.org/10.1037/xge0000107

Faul, F., Erdfelder, E., Lang, A.-G., \& Buchner, A. (2007). G*Power 3: A flexible statistical power analysis program for the social, behavioral, and biomedical sciences. Behavior Research Methods, 39, 175-191. doi: 10.3758/BF03193146

Fiedler, S., Glöckner, A., Nicklisch, A., \& Dickert, S. (2013). Social value orientation and information search in social dilemmas: An eye-tracking analysis. Organizational Behavior and Human Decision Processes, 120, 272-284. doi: 10.1016/j.obhdp.2012.07.002

Fischbacher, U. (2007). z-Tree: Zurich toolbox for ready-made economic experiments. Experimental Economics, 10, 171-178. doi: 10.1007/s10683-006-9159-4

Gärling, T., Fujii, S., Gärling, A., \& Jakobsson, C. (2003). Moderating effects of social value orientation on determinants of proenvironmental behavior intention. Journal of Environmental Psychology, 23, 1-9. doi: 10.1016/S0272-4944(02)00081-6

Glöckner, A., \& Betsch, T. (2008). Multiple-reason decision making based on automatic processing. Journal of Experimental Psychology: Learning, Memory, and Cognition, 34, 1055-1075. doi: 10.1037/0278-7393.34.5.1055

Glöckner, A., \& Herbold, A.-K. (2011). An eye-tracking study on information processing in risky decisions: Evidence for compensatory strategies based on automatic processes. Journal of Behavioral Decision Making, 24, 71-98. https://doi.org/10.1002/bdm.684

Gollwitzer, P. M. (1999). Implementation intentions: Strong effects of simple plans. American Psychologist, 54, 493-503.

Gollwitzer, P. M. (2014). Weakness of the will: Is a quick fix possible? Motivation and Emotion, 38, 305-322. doi: 10.1007/s11031-014-9416-3

Gosling, S. D., \& Mason, W. (2015). Internet research in psychology. Annual Review of Psychology, 66, 877-902. doi: 10.1146/annurev-psych-010814-015321

Hallsson, B. G., Siebner, H. R., \& Hulme, O. J. (2018). Fairness, fast and slow: A review of dual process models of fairness. Neuroscience and Biobehavioral Reviews, 89, 49-60. https://doi.org/10.1016/j.neubiorev.2018.02.016

Hochman, G., Ayal, S., \& Ariely, D. (2015). Fairness requires deliberation: The primacy of economic over social considerations. Frontiers in Psychology, 6, 747. doi: 10.3389/fpsyg.2015.00747 
Johnson, E. J., Camerer, C., Sen, S., \& Rymon, T. (2002). Detecting failures of backward induction: Monitoring information search in sequential bargaining. Journal of Economic Theory, 104, 16-47. doi: 10.1006/jeth.2001.2850

Kaufmann, N., Schulze, T., \& Veit, D. (2011). More than fun and money. Worker motivation in crowdsourcing - A study on Mechanical Turk. In N. King (Ed.), Proceedings of the seventeenth Americas conference on information systems: A service value approach to the micro-organizational networks of e-prescribing. Detroit, MI: Association for Information Systems. Retrieved from https://aisel.aisnet.org/amcis2011_submissions/340/

Kelley, H. H., \& Thibaut, J. W. (1978). Interpersonal relations: A theory of interdependence. New York: John Wiley \& Sons.

Klein, H. J., Wesson, M. J., Hollenbeck, J. R., Wright, P. M., \& DeShon, R. P. (2001). The assessment of goal commitment: A measurement model meta-analysis. Organizational Behavior and Human Decision Processes, 85, 32-55. doi: 10.1006/obhd.2000.2931

Krajbich, I., Armel, C., \& Rangel, A. (2010). Visual fixations and the computation and comparison of value in simple choice. Nature Neuroscience, 13, 1292-1298. doi: 10.1038/nn.2635

Krajbich, I., Bartling, B., Hare, T., \& Fehr, E. (2015). Rethinking fast and slow based on a critique of reaction-time reverse inference. Nature Communications, 6, 7455. https://doi.org/10.1038/ncomms 8455

Krajbich, I., Lu, D., Camerer, C., \& Rangel, A. (2012). The attentional drift-diffusion model extends to simple purchasing decisions. Frontiers in Psychology, 3, 193. doi:

10.3389/fpsyg.2012.00193

Kraut, R., Olson, J., Banaji, M., Bruckman, A., Cohen, J., \& Couper, M. (2004). Psychological research online: Report of Board of Scientific Affairs' Advisory Group on the conduct of research on the internet. American Psychologist, 59, 105-117. doi: 10.1037/0003066X.59.2.105

Liebrand, W. B. G., \& McClintock, C. G. (1988). The ring measure of social values: A computerized procedure for assessing individual differences in information processing and social value orientation. European Journal of Personality, 2, 217-230. doi: 10.1002/per.2410020304

Liebrand, W. B.G. (1984). The effect of social motives, communication and group size on behaviour in an N-person multi-stage mixed-motive game. European Journal of Social Psychology, 14, 239-264.

Lohse, G. L., \& Johnson, E. J. (1996). A comparison of two process tracing methods for choice tasks. Organizational Behavior and Human Decision Processes, 68, 28-43. doi: 10.1109/HICSS.1996.495316

Martiny-Huenger, T., Bieleke, M., Oettingen, G., \& Gollwitzer, P. M. (2017). From thought to automatic action: Strategic and spontaneous action control by if-then planning. In R. Deutsch, B. Gawronski, \& W. Hofmann (Eds.), Reflective and impulsive determinants of behavior (pp. 69-84). New York, NY: Routledge.

McClintock, C. G., \& Liebrand, W. B. G. (1988). Role of interdependence structure, individual value orientation, and another's strategy in social decision making: A transformational analysis. Journal of Personality and Social Psychology, 55, 396-409. 
Messick, D. M., \& McClintock, C. G. (1968). Motivational bases of choice in experimental games. Journal of Experimental Social Psychology, 4, 1-25.

Mischkowski, D., \& Glöckner, A. (2016). Spontaneous cooperation for prosocials, but not for proselfs: Social value orientation moderates spontaneous cooperation behavior. Scientific Reports, 6, 21555. doi: 10.1038/srep21555

Mitchell, D. J., Kahn, B. E., \& Knasko, S. C. (1995). There's something in the air: Effects of congruent or incongruent ambient odor on consumer decision making. Journal of Consumer Research, 22, 229-238.

Murphy, R. O., \& Ackermann, K. A. (2014). Social value orientation: Theoretical and measurement issues in the study of social preferences. Personality and Social Psychology Review, 18, 13-41. doi: 10.1177/1088868313501745

Murphy, R. O., Ackermann, K. A., \& Handgraaf, M. (2011). Measuring social value orientation. Judgment and Decision Making, 6, 771-781.

Norman, E., \& Schulte-Mecklenbeck, M. (2010). Take a quick click at that! Mouselab and eyetracking as tools to measure intuition. In A. Glöckner \& C. Witteman (Eds.), Foundations for tracing intuition: Challenges and methods (pp. 24-44). New York, NY: Psychology Press.

Oettingen, G. (2012). Future thought and behaviour change. European Review of Social Psychology, 23, 1-63. doi: 10.1080/10463283.2011.643698

Oettingen, G. (2014). Rethinking positive thinking: Inside the new science of motivation. New York, NY: Penguin Random House.

Oettingen, G., Pak, H.-j., \& Schnetter, K. (2001). Self-regulation of goal-setting: Turning free fantasies about the future into binding goals. Journal of Personality and Social Psychology, 80, 736-753. doi: 10.1037/0022-3514.80.5.736

Payne, J. W., \& Braunstein, M. L. (1978). Risky choice: An examination of information acquisition behavior. Memory \& Cognition, 6, 554-561. doi: 10.3758/BF03198244

Payne, J. W., Bettman, J. R., \& Johnson, E. J. (1988). Adaptive strategy selection in decision making. Journal of Experimental Psychology: Learning, Memory, and Cognition, 14, 534552.

Payne, J. W., Bettman, J. R., \& Johnson, E. J. (1993). The adaptive decision maker. New York, NY: Cambridge University Press.

Peirce, J. W. (2007). PsychoPy-Psychophysics software in Python. Journal of Neuroscience Methods, 162, 8-13. doi: 10.1016/j.jneumeth.2006.11.017

Peirce, J. W. (2009). Generating stimuli for neuroscience using PsychoPy. Frontiers in Neuroinformatics, 2, 10. doi: 10.3389/neuro.11.010.2008

Rand, D. G. (2016). Cooperation, fast and slow: Meta-analytic evidence for a theory of social heuristics and self-interested deliberation. Psychological Science, 27, 1192-1206. https://doi.org/10.1177/0956797616654455

Rand, D. G., Greene, J. D., \& Nowak, M. A. (2012). Spontaneous giving and calculated greed. Nature, 489, 427-430. doi: 10.1038/nature11467

Reisen, N., Hoffrage, U., \& Mast, F. W. (2008). Identifying decision strategies in a consumer choice situation. Judgment and Decision Making, 3, 641-658. 
Rieskamp, J., \& Hoffrage, U. (1999). When do people use simple heuristics, and how can we tell? In G. Gigerenzer, P. M. Todd, \& the ABC Research Group (Eds.), Simple heuristics that make us smart (pp. 141-167). Oxford: Oxford University Press.

Rubinstein, A. (2007). Instinctive and cognitive reasoning: A study of response times. The Economic Journal, 117, 1243-1259. doi: 10.1111/j.1468-0297.2007.02081.x

Schönbrodt, F. D., \& Perugini, M. (2013). At what sample size do correlations stabilize? Journal of Research in Personality, 47, 609-612. https://doi.org/10.1016/j.jrp.2013.05.009

Schulte-Mecklenbeck, M., Johnson, J. G., Böckenholt, U., Goldstein, D. G., Russo, J. E., Sullivan, N. J., \& Willemsen, M. C. (2017). Process-tracing methods in decision making: On growing up in the 70s. Current Directions in Psychological Science, 26, 442-450. doi: 10.1177/0963721417708229

Schulte-Mecklenbeck, M., Kühberger, A., \& Ranyard, R. (2011). The role of process data in the development and testing of process models of judgment and decision making. Judgment and Decision Making, 6, 733-739.

Schulz, J. F., Fischbacher, U., Thöni, C., \& Utikal, V. (2014). Affect and fairness: Dictator games under cognitive load. Journal of Economic Psychology, 41, 77-87. doi: 10.1016/j.joep.2012.08.007

Shimojo, S., Simion, C., Shimojo, E., \& Scheier, C. (2003). Gaze bias both reflects and influences preference. Nature Neuroscience, 6, 1317-1322. doi: 10.1038/nn1150

Sütterlin, B., Brunner, T. A., \& Opwis, K. (2008). Eye-tracking the cancellation and focus model for preference judgments. Journal of Experimental Social Psychology, 44, 904-911. https://doi.org/10.1016/j.jesp.2007.09.003

Sütterlin, B., Brunner, T. A., \& Siegrist, M. (2013). Impact of social value orientation on energy conservation in different behavioral domains. Journal of Applied Social Psychology, 43, 1725-1735. doi: 10.1111/jasp.12128

Towal, R. B., Mormann, M., \& Koch, C. (2013). Simultaneous modeling of visual saliency and value computation improves predictions of economic choice. PNAS, 110, E3858-67. doi: 10.1073/pnas. 1304429110

van Lange, P. A. M., Agnew, C. R., Harinck, F., \& Steemers, G. E. M. (1997). From game theory to real life: How social value orientation affects willingness to sacrifice in ongoing close relationships. Journal of Personality and Social Psychology, 73, 1330-1344. doi: 10.1037/0022-3514.73.6.1330

van Lange, P. A. M., Bekkers, R., Chirumbolo, A., \& Leone, L. (2012). Are conservatives less likely to be prosocial than liberals? From games to ideology, political preferences and voting. European Journal of Personality, 26, 461-473. doi: 10.1002/per.845

van Lange, P. A. M., Bekkers, R., Schuyt, T. N. M., \& van Vugt, M. (2007). From games to giving: Social value orientation predicts donations to noble causes. Basic and Applied Social Psychology, 29, 375-384. doi: 10.1080/01973530701665223

Voss, A., Nagler, M., \& Lerche, V. (2013). Diffusion models in experimental psychology: a practical introduction. Experimental psychology, 60, 385-402. doi: 10.1027/16183169/a000218

Willemsen, M. C., \& Johnson, E. J. (2008). MouselabWEB. Retrieved from http://www.Mouselabweb.org/index.html 
Willemsen, M. C., \& Johnson, E. J. (2011). Visiting the decision factory: Observing cognition with MouselabWEB and other information acquisition tools. In M. Schulte-Mecklenbeck, A. Kühberger, \& R. Ranyard (Eds.), A handbook of process tracing methods for decision research (pp. 21-42). New York, NY: Psychology Press. 


\section{Footnotes}

${ }^{1}$ Note that this is not necessarily true in the Ring Task because SVO scores exceeding a value of 90 would correspond to lower prosociality again. However, such values were not observed in the present experiments and therefore the interpretation of higher SVO scores as indicating more prosociality holds true for our data.

${ }^{2}$ We used the time until participants left the last box prior to their decision to determine decision time.

${ }^{3}$ We could not compute the number of unique acquisitions and the transition index for the first item of the Slider Task and thus coded these acquisitions as missing. The reason is that we only saved the payoffs participants inspected (e.g., 50 points) but no direct identifiers of the corresponding boxes (e.g., Box 3). This is no issue for most items of the Slider Task, in which boxes are associated with unique payoffs. It is, however, a problem for the first item because the own payoff in this case was always 85 points and the corresponding box was therefore not determinable without a direct box identifier.

${ }^{4} \mathrm{We}$ also ran an exploratory analysis in which we regressed the five information acquisition indices on the original SVO scores of prosocial and competitive participants. However, this SVO score did not predict information acquisition in the Ring Task nor in the Slider Task, $p>.33$, suggesting no reliable differences between competitors and prosocials in our data. This is in line with the study by Fiedler et al. (2013) who found no differences between negative and positive SVO scores with regard to information acquisition. 
Table 1

Predicting information acquisition in the Ring Task and in the Slider Task by absolute SVO scores from the Ring Task in Experiment 1.

\begin{tabular}{|c|c|c|c|c|c|}
\hline & $\begin{array}{c}\log \\
\text { decision time }\end{array}$ & $\begin{array}{c}\log \text { total \# of } \\
\text { acquisitions }\end{array}$ & $\begin{array}{l}\log \# \text { of unique } \\
\text { acquisitions }\end{array}$ & $\begin{array}{l}\% \text { acquisition of } \\
\text { other's payoff }\end{array}$ & $\begin{array}{c}\text { Transition } \\
\text { index }\end{array}$ \\
\hline \multicolumn{6}{|c|}{ Ring Task (within-task prediction) } \\
\hline \multirow[t]{2}{*}{ Intercept } & $1.425^{* * *}$ & $1.564^{* * *}$ & $1.140^{* * *}$ & $42.419^{* * * *}$ & 0.239 \\
\hline & $(0.110)$ & $(0.097)$ & $(0.049)$ & $(4.023)$ & $(0.157)$ \\
\hline \multirow[t]{2}{*}{ abs(SVO) } & $0.010^{* *}$ & $0.005^{\circ}$ & $0.004^{* *}$ & $0.297^{*}$ & $0.016^{* *}$ \\
\hline & $(0.004)$ & $(0.003)$ & $(0.001)$ & $(0.122)$ & $(0.005)$ \\
\hline \multirow[t]{2}{*}{ Trial } & $-0.015^{* * *}$ & $-0.007^{\circ}$ & 0.001 & -0.194 & -0.008 \\
\hline & $(0.004)$ & $(0.004)$ & $(0.002)$ & $(0.162)$ & $(0.005)$ \\
\hline$\overline{A d j .} R^{2}$ & 0.082 & 0.022 & 0.007 & 0.015 & 0.028 \\
\hline$N$ & 575 & 575 & 575 & 575 & 571 \\
\hline \multicolumn{6}{|c|}{ Slider Task (between-task prediction) } \\
\hline \multirow[t]{2}{*}{ Intercept } & $2.438^{* * *}$ & $3.013^{* * *}$ & $2.852^{* * *}$ & $40.641^{* * *}$ & $-0.281^{\circ}$ \\
\hline & $(0.087)$ & $(0.070)$ & $(0.089)$ & $(4.026)$ & $(0.158)$ \\
\hline \multirow[t]{2}{*}{ abs(SVO) } & $0.013^{* *}$ & $0.009^{* * *}$ & $0.005^{*}$ & $0.339^{* *}$ & $0.014^{* *}$ \\
\hline & $(0.004)$ & $(0.003)$ & $(0.002)$ & $(0.114)$ & $(0.005)$ \\
\hline \multirow[t]{2}{*}{ Trial } & $-0.070^{* * *}$ & $-0.064^{* * *}$ & $-0.113^{* * *}$ & $-2.126^{* *}$ & 0.021 \\
\hline & $(0.019)$ & $(0.016)$ & $(0.021)$ & $(0.721)$ & $(0.019)$ \\
\hline$\overline{A d j .} R^{2}$ & 0.158 & 0.133 & 0.205 & 0.119 & 0.043 \\
\hline$N$ & 144 & 144 & 120 & 144 & 120 \\
\hline
\end{tabular}

Note. Numbers in parentheses are robust standard errors clustered on the individual level (24 clusters). ${ }^{* * *} p<.001,{ }^{* *} p<.01,{ }^{*} p<.05, \stackrel{\circ}{p} p<.10$. 
Table 2

Predicting information acquisition in the Ring Task and in the Slider Task by absolute SVO scores from the Ring Task and decision mode condition in Experiment 2. The control condition serves as baseline in the analysis of the Slider Task.

\begin{tabular}{|c|c|c|c|c|c|c|c|c|c|c|}
\hline \multirow{2}{*}{\multicolumn{3}{|c|}{$\begin{array}{l}\text { log } \\
\text { decision time }\end{array}$}} & \multicolumn{2}{|c|}{$\begin{array}{l}\log \text { total \# of } \\
\text { acquisitions }\end{array}$} & \multicolumn{2}{|c|}{$\begin{array}{l}\log \# \text { of unique } \\
\text { acquisitions }\end{array}$} & \multicolumn{2}{|c|}{$\begin{array}{c}\% \text { acquisition of } \\
\text { other's payoff }\end{array}$} & \multicolumn{2}{|c|}{$\begin{array}{l}\text { Transition } \\
\text { index }\end{array}$} \\
\hline & & & & & & & & & & \\
\hline \multirow[t]{2}{*}{ Intercept } & \multicolumn{2}{|c|}{$1.626^{* * *}$} & & \multirow{2}{*}{\multicolumn{2}{|c|}{$\begin{array}{l}1.261^{* * *} \\
(0.024)\end{array}$}} & \multicolumn{2}{|l|}{$44.364^{* * *}$} & \multirow{2}{*}{\multicolumn{2}{|c|}{$\begin{array}{l}0.349^{* * *} \\
(0.071)\end{array}$}} \\
\hline & $(0.047)$ & & $(0.044)$ & & & & $(1.878)$ & & & \\
\hline \multirow[t]{2}{*}{ abs(SVO) } & \multicolumn{2}{|l|}{$0.009^{* * *}$} & \multicolumn{2}{|l|}{$0.008^{* * *}$} & \multicolumn{2}{|l|}{$0.003^{* * *}$} & \multicolumn{2}{|l|}{$0.250^{* * *}$} & \multicolumn{2}{|l|}{$0.007^{* * *}$} \\
\hline & \multicolumn{2}{|l|}{$(0.001)$} & \multicolumn{2}{|l|}{$(0.001)$} & \multicolumn{2}{|l|}{$(0.001)$} & \multicolumn{2}{|l|}{$(0.052)$} & \multicolumn{2}{|l|}{$(0.002)$} \\
\hline \multirow[t]{2}{*}{ Trial } & \multirow{2}{*}{\multicolumn{2}{|c|}{$\begin{array}{l}-0.018^{* * *} \\
(0.002)\end{array}$}} & \multirow{2}{*}{\multicolumn{2}{|c|}{$\begin{array}{l}-0.010^{* * *} \\
(0.002)\end{array}$}} & \multirow{2}{*}{\multicolumn{2}{|c|}{$\begin{array}{l}-0.005^{\text {**** }} \\
(0.001)\end{array}$}} & \multirow{2}{*}{\multicolumn{2}{|c|}{$\begin{array}{l}-0.214^{* * *} \\
(0.061)\end{array}$}} & \multirow{2}{*}{\multicolumn{2}{|c|}{$\begin{array}{l}-0.009^{* * * *} \\
(0.002)\end{array}$}} \\
\hline & & & & & & & & & & \\
\hline$A d j . R^{2}$ & \multicolumn{2}{|l|}{0.098} & \multicolumn{2}{|l|}{0.038} & 0.040 & & 0.024 & & 0.021 & \\
\hline$N$ & 2874 & & 2874 & & 2874 & & 2874 & & 2829 & \\
\hline Slider Task (be & een-task prec & diction) & & & & & & & & \\
\hline Intercept & $2.532^{* * *}$ & $2.624^{* * *}$ & $3.029^{* * * *}$ & $3.112^{* * *}$ & $2.578^{* * * *}$ & $2.581^{* * * *}$ & $42.182^{* * *}$ & $42.865^{* * *}$ & 0.031 & 0.061 \\
\hline & $(0.044)$ & $(0.088)$ & $(0.044)$ & $(0.071)$ & $(0.042)$ & $(0.066)$ & $(1.764)$ & $(3.239)$ & $(0.072)$ & $(0.122)$ \\
\hline $\operatorname{abs}(\mathrm{SVO})$ & $0.008^{* * *}$ & $0.006^{*}$ & $0.006^{* * *}$ & $0.004^{*}$ & $0.005^{* * *}$ & $0.006^{* * *}$ & $0.333^{* * *}$ & $0.306^{* *}$ & $0.011^{* * *}$ & $0.007^{\circ}$ \\
\hline & $(0.001)$ & $(0.003)$ & $(0.001)$ & $(0.002)$ & $(0.001)$ & $(0.002)$ & $(0.049)$ & $(0.099)$ & $(0.002)$ & $(0.004)$ \\
\hline Trial & $-0.031^{* *}$ & $-0.031^{* *}$ & $-0.023^{* *}$ & $-0.023^{* *}$ & $-0.061^{* * *}$ & $-0.061^{* * *}$ & $-1.009^{* * *}$ & $-1.009^{* * *}$ & 0.012 & 0.012 \\
\hline & $(0.010)$ & $(0.010)$ & $(0.009)$ & $(0.009)$ & $(0.009)$ & $(0.009)$ & $(0.272)$ & $(0.272)$ & $(0.010)$ & $(0.010)$ \\
\hline Condition $=$ & & -0.134 & & -0.103 & & -0.036 & & -2.814 & & -0.086 \\
\hline Intuition & & $(0.124)$ & & $(0.112)$ & & $(0.099)$ & & $(4.509)$ & & $(0.162)$ \\
\hline Condition $=$ & & -0.148 & & $-0.164^{\circ}$ & & 0.023 & & 1.572 & & 0.051 \\
\hline Reflection & & $(0.124)$ & & $(0.092)$ & & $(0.099)$ & & $(5.309)$ & & $(0.197)$ \\
\hline $\operatorname{abs}(\mathrm{SVO}) \times$ & & 0.002 & & 0.000 & & -0.002 & & 0.048 & & 0.007 \\
\hline Intuition & & $(0.004)$ & & $(0.003)$ & & $(0.003)$ & & $(0.121)$ & & $(0.005)$ \\
\hline $\operatorname{abs}(\mathrm{SVO}) \times$ & & 0.004 & & $0.005^{*}$ & & -0.002 & & 0.002 & & 0.004 \\
\hline Reflection & & $(0.004)$ & & $(0.002)$ & & $(0.003)$ & & $(0.136)$ & & $(0.005)$ \\
\hline$A d j . R^{2}$ & 0.053 & 0.051 & 0.041 & 0.044 & 0.114 & 0.111 & 0.086 & 0.083 & 0.050 & 0.050 \\
\hline$N$ & 720 & 720 & 720 & 720 & 720 & 720 & 720 & 720 & 717 & 717 \\
\hline
\end{tabular}

Note. Numbers in parentheses are robust standard errors clustered on individuals. ${ }^{* * * *} p<.001,{ }^{* * *} p<.01,{ }^{*} p<.05,{ }^{\circ} p<.10$. 
Table 3

The effect of intuitive versus reflective decision modes on the five indicators of information acquisition in Experiment 2. The intuitive condition serves as baseline.

\begin{tabular}{|c|c|c|c|c|c|c|c|c|c|c|c|c|}
\hline \multirow[b]{3}{*}{ Intercept } & \multicolumn{10}{|c|}{ Information acquisition } & \multirow{2}{*}{\multicolumn{2}{|c|}{ SVO score }} \\
\hline & \multicolumn{2}{|c|}{$\begin{array}{c}\log \\
\text { decision time }\end{array}$} & \multicolumn{2}{|c|}{$\begin{array}{l}\log \text { total \# of } \\
\text { acquisitions }\end{array}$} & \multicolumn{2}{|c|}{$\begin{array}{c}\log \# \text { of unique } \\
\text { acquisitions }\end{array}$} & \multicolumn{2}{|c|}{$\begin{array}{c}\% \text { acquisition of } \\
\text { other's payoff }\end{array}$} & \multicolumn{2}{|c|}{$\begin{array}{c}\text { Transition } \\
\text { index }\end{array}$} & & \\
\hline & $\begin{array}{l}2.658^{* * *} \\
(0.062)\end{array}$ & $\begin{array}{c}2.089^{* * *} \\
(0.204)\end{array}$ & $\begin{array}{l}3.111^{* * * *} \\
(0.061)\end{array}$ & $\begin{array}{c}2.675^{\text {*** }} \\
(0.207)\end{array}$ & $\begin{array}{l}2.642^{* * *} \\
(0.054)\end{array}$ & $\begin{array}{c}2.179^{* * *} \\
(0.176)\end{array}$ & $\begin{array}{l}47.969^{* * *} \\
(2.202)\end{array}$ & $\begin{array}{l}24.610^{\text {**** }} \\
(8.104)\end{array}$ & $\begin{array}{l}0.287^{* *} \\
(0.090)\end{array}$ & $\begin{array}{c}-0.649^{*} \\
(0.277)\end{array}$ & $\begin{array}{l}21.512^{* *} \\
(2.638)\end{array}$ & $\begin{array}{l}11.474 \\
(8.388)\end{array}$ \\
\hline Trial & $\begin{array}{l}-0.031^{* *} \\
(0.010)\end{array}$ & $\begin{array}{l}-0.026^{* *} \\
(0.012)\end{array}$ & $\begin{array}{c}-0.023^{* *} \\
(0.009)\end{array}$ & $\begin{array}{l}-0.021^{\circ} \\
(0.011)\end{array}$ & $\begin{array}{l}-0.061^{\text {**** }} \\
(0.009)\end{array}$ & $\begin{array}{c}-0.056^{* * *} \\
(0.010)\end{array}$ & $\begin{array}{l}-1.009^{* * *} \\
(0.272)\end{array}$ & $\begin{array}{l}-0.868^{*} \\
(0.342)\end{array}$ & $\begin{array}{c}0.012 \\
(0.010)\end{array}$ & $\begin{array}{c}0.009 \\
(0.012)\end{array}$ & & \\
\hline $\begin{array}{l}\text { Condition }= \\
\text { Control }\end{array}$ & $\begin{array}{c}0.086 \\
(0.090)\end{array}$ & & $\begin{array}{c}0.091 \\
(0.075)\end{array}$ & & $\begin{array}{c}0.069 \\
(0.068)\end{array}$ & & $\begin{array}{c}1.332 \\
(3.022)\end{array}$ & & $\begin{array}{l}-0.081 \\
(0.114)\end{array}$ & & $\begin{array}{c}0.343 \\
(3.698)\end{array}$ & \\
\hline $\begin{array}{l}\text { Condition }= \\
\text { Reflection }\end{array}$ & $\begin{array}{c}0.106 \\
(0.088)\end{array}$ & $\begin{array}{c}0.205^{*} \\
(0.095)\end{array}$ & $\begin{array}{c}0.109 \\
(0.075)\end{array}$ & $\begin{array}{c}0.200^{*} \\
(0.100)\end{array}$ & $\begin{array}{c}0.075 \\
(0.068)\end{array}$ & $\begin{array}{c}0.182^{*} \\
(0.086)\end{array}$ & $\begin{array}{c}5.461^{\circ} \\
(3.002)\end{array}$ & $\begin{array}{c}9.961^{* *} \\
(3.059)\end{array}$ & $\begin{array}{c}0.145 \\
(0.116)\end{array}$ & $\begin{array}{c}0.341^{* *} \\
(0.113)\end{array}$ & $\begin{array}{c}8.105^{*} \\
(3.535)\end{array}$ & $\begin{array}{l}10.144^{*} \\
(3.995)\end{array}$ \\
\hline Commitment & & $\begin{array}{l}0.079^{* *} \\
(0.025)\end{array}$ & & $\begin{array}{c}0.065^{* *} \\
(0.021)\end{array}$ & & $\begin{array}{c}0.050^{*} \\
(0.019)\end{array}$ & & $\begin{array}{l}2.872^{* *} \\
(1.041)\end{array}$ & & $\begin{array}{l}0.119^{* *} \\
(0.039)\end{array}$ & & $\begin{array}{c}1.197 \\
(1.116)\end{array}$ \\
\hline $\begin{array}{l}\text { General } \\
\text { Relevance }\end{array}$ & & $\begin{array}{c}0.027 \\
(0.034)\end{array}$ & & $\begin{array}{c}0.031 \\
(0.032)\end{array}$ & & $\begin{array}{c}0.048^{\circ} \\
(0.029)\end{array}$ & & $\begin{array}{c}1.587^{\circ} \\
(0.843)\end{array}$ & & $\begin{array}{c}0.073^{*} \\
(0.034)\end{array}$ & & $\begin{array}{c}0.769 \\
(1.287)\end{array}$ \\
\hline $\begin{array}{l}\text { Specific } \\
\text { Relevance }\end{array}$ & & $\begin{array}{c}0.026 \\
(0.039) \\
\end{array}$ & & $\begin{array}{c}-0.002 \\
(0.027) \\
\end{array}$ & & $\begin{array}{c}0.003 \\
(0.029) \\
\end{array}$ & & $\begin{array}{c}0.996 \\
(1.542) \\
\end{array}$ & & $\begin{array}{c}0.030 \\
(0.057) \\
\end{array}$ & & $\begin{array}{r}0.432 \\
(1.636) \\
\end{array}$ \\
\hline$\overline{A d j .} R^{2}$ & 0.017 & 0.025 & 0.010 & 0.018 & 0.096 & 0.098 & 0.027 & 0.039 & 0.004 & 0.023 & 0.037 & 0.032 \\
\hline$N$ & 720 & 480 & 720 & 480 & 720 & 480 & 720 & 480 & 717 & 477 & 120 & 80 \\
\hline
\end{tabular}

Note. Numbers in parentheses are robust standard errors clustered on individuals. ${ }^{* * *} p<.001,{ }^{* *} p<.01,{ }^{*} p<.05,{ }^{\circ} p<.10$. 


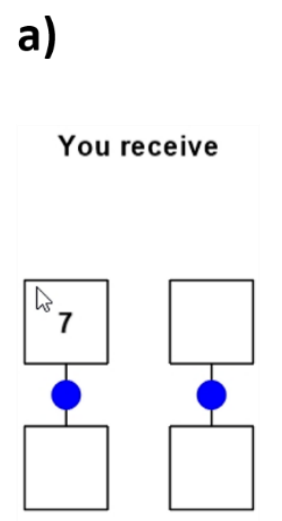

Other receives b)

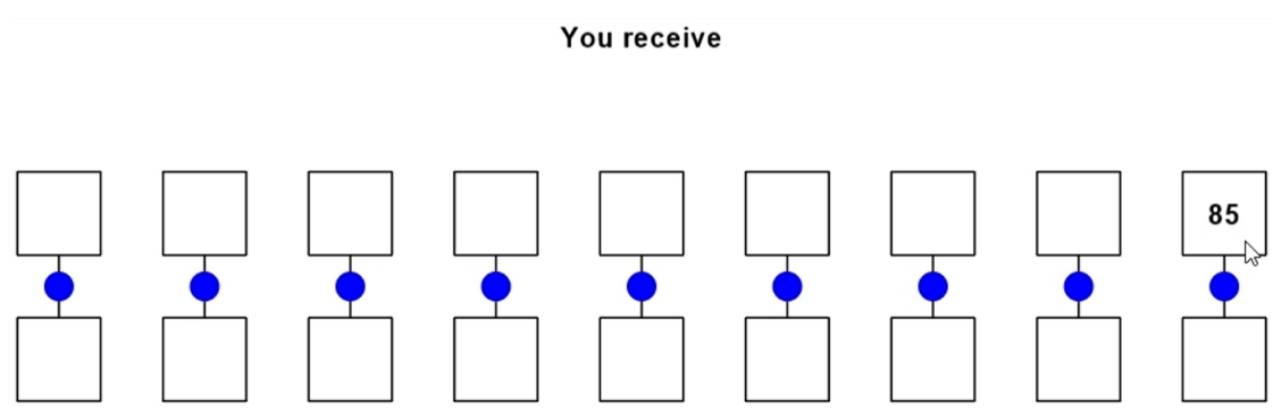

Other receives

Fig. 1. Example of the stimuli used in a) the Ring Task (binary-choice options) and b) the Slider Task (nine choice options). Boxes belonging to the same allocation were connected by a line with a blue dot at the middle of it. Participants moved the mouse cursor over a box to acquire payoff information and clicked on the blue dots to select an allocation. 


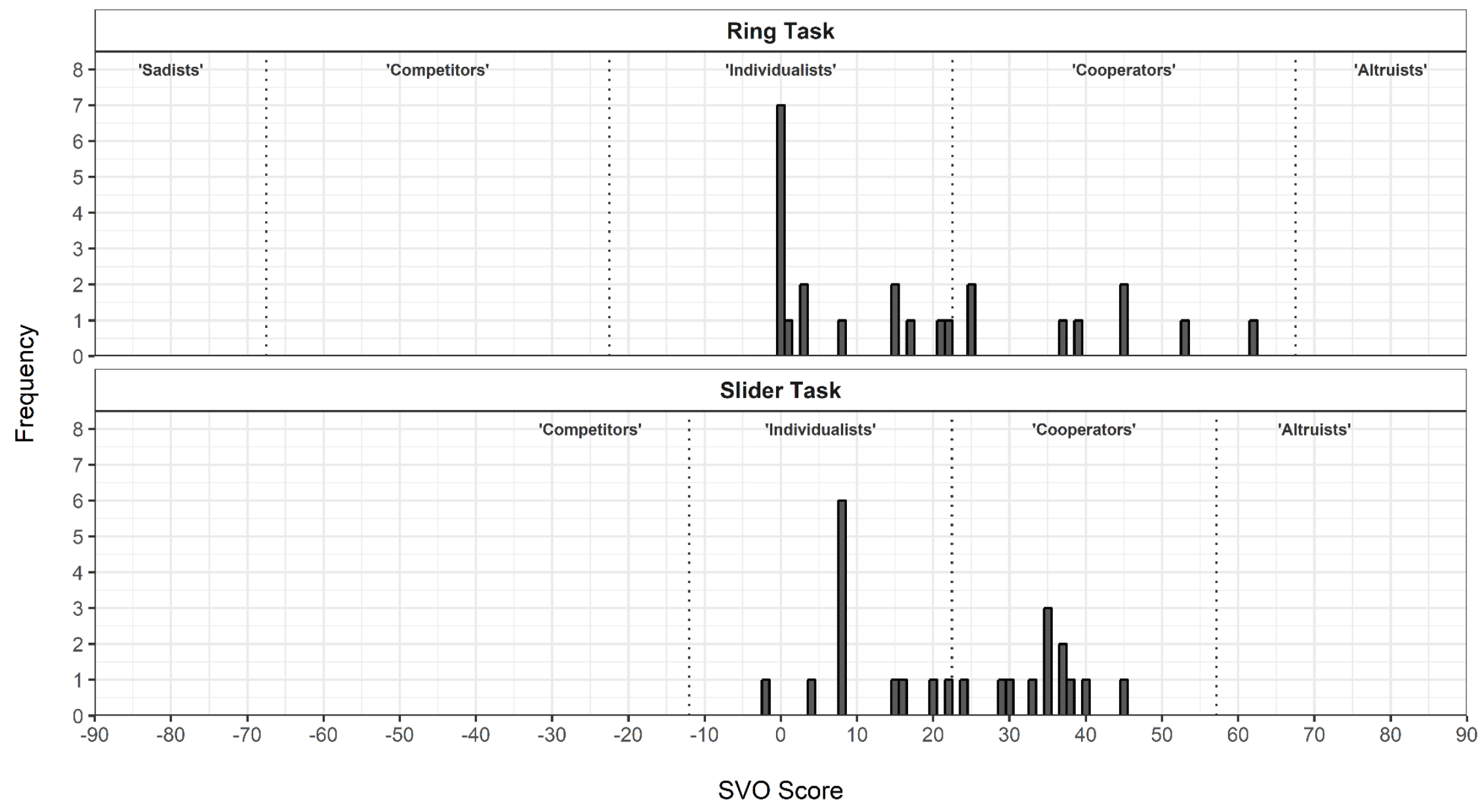

Fig. 2. Distribution of SVO scores in the Ring Task and in the Slider Task in Experiment 1. Dotted lines denote boundaries for the nominal classifications. 

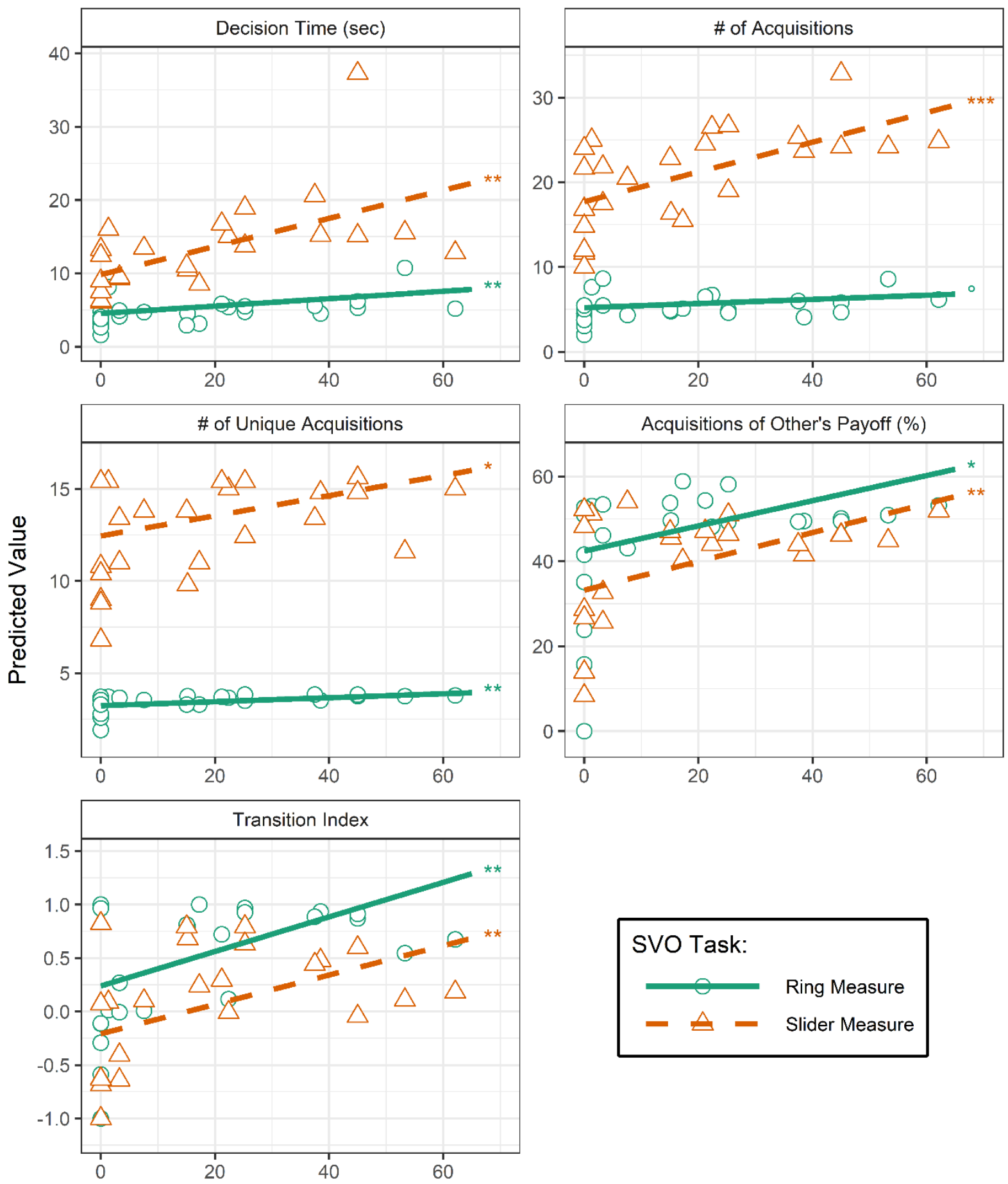

SVO Task:

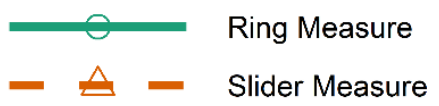

Absolute SVO Score from Ring Measure

Fig. 3. Information acquisition in the Ring and the Slider Task is predicted by the absolute SVO score derived from choices in the Ring Task in Experiment 1. For drawing predictions, we reestimated the models reported in Table 1 without log-transformation of the dependent variables (i.e., using untransformed data). Accordingly, each line shows predicted values across the range of absolute ring scores in original units, while holding the trial number constant. Significance is based on the analyses reported in the text and in Table 1. Circles and triangles represent individual averages. 


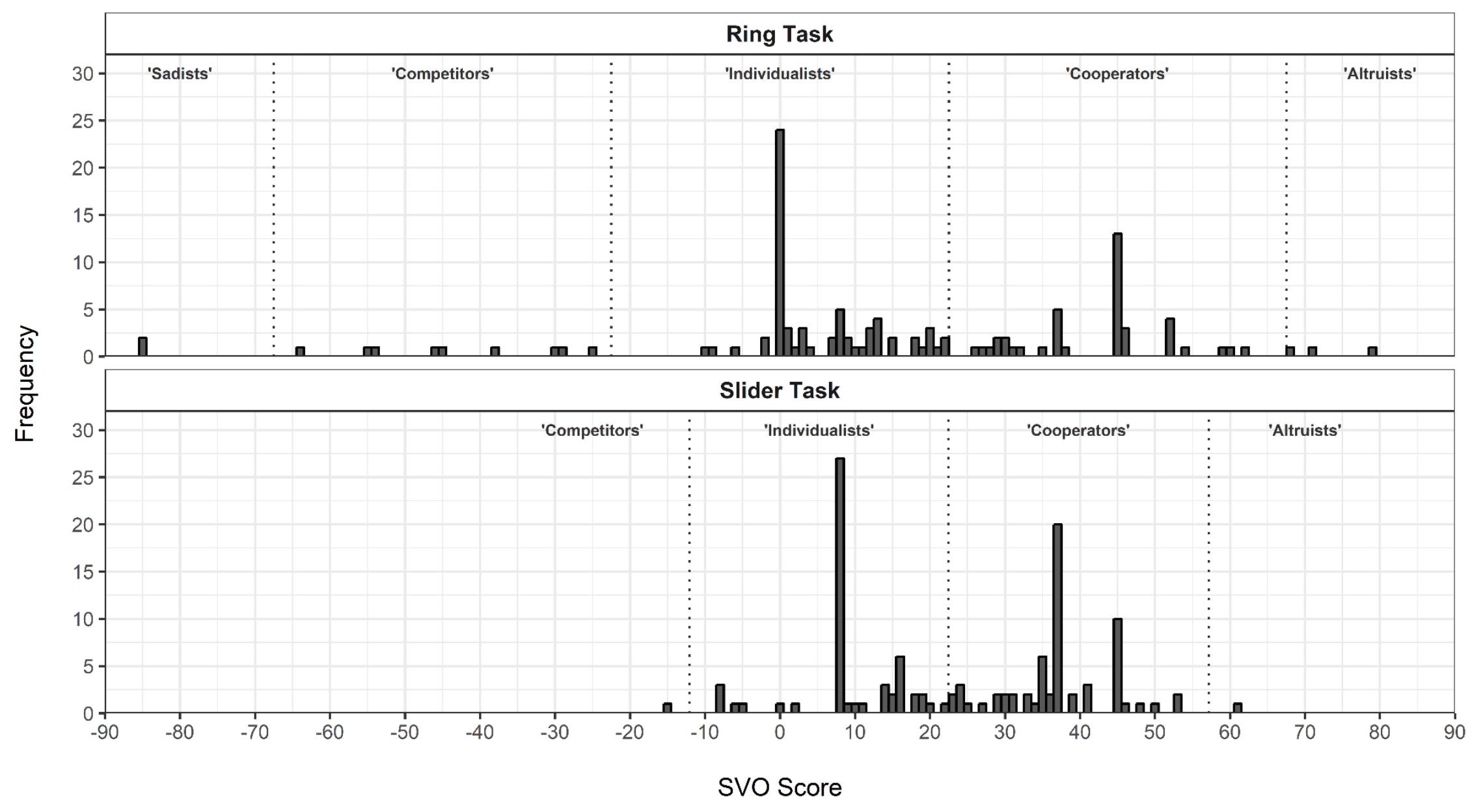

Fig. 4. Distribution of SVO scores in the Ring Task and the Slider Task in Experiment 2. Dotted lines denote boundaries for the nominal classifications. 


\section{Supplementary Information 1 - Items used in the SVO Tasks}

\section{Ring Task}

Example
\begin{tabular}{|lcc|}
\hline Self & 90 & 100 \\
& $\mid$ & $\mid$ \\
Other & 0 & 80 \\
\hline
\end{tabular}

\section{Item 4}

\begin{tabular}{|lcc|}
\hline Self & 15 & 25 \\
& I & I \\
Other & 15 & 7 \\
\hline
\end{tabular}

\section{Item 8}

\begin{tabular}{|lcc|}
\hline Self & 63 & 75 \\
& 1 & $!$ \\
Other & 2 & 7 \\
\hline
\end{tabular}

Item 12

\begin{tabular}{|lcc|}
\hline Self & 7 & 2 \\
& $\mid$ & $\mid$ \\
Other & 75 & 63 \\
\hline
\end{tabular}

Item 16

\begin{tabular}{|lcc|}
\hline Self & 0 & 2 \\
& $\mid$ & $\mid$ \\
Other & 50 & 37 \\
\hline
\end{tabular}

Item 20

\begin{tabular}{|lcc|}
\hline Self & 37 & 50 \\
& $\mid$ & $\mid$ \\
Other & 2 & 0 \\
\hline
\end{tabular}

\section{Item 24}

\begin{tabular}{|lcc|}
\hline Self & 98 & 93 \\
& $\quad$ & $\mid$ \\
Other & 63 & 75 \\
\hline
\end{tabular}

Item 1

\begin{tabular}{|lcc|}
\hline Self & 2 & 7 \\
& $\mid$ & $\mid$ \\
Other & 37 & 25 \\
\hline
\end{tabular}

Item 2

\begin{tabular}{|ccc|}
\hline Self & 85 & 93 \\
& $\mid$ & $\mid$ \\
Other & 15 & 25 \\
\hline
\end{tabular}

Item 5

\begin{tabular}{|lcc|}
\hline Self & 25 & 37 \\
& $\mid$ & $\mid$ \\
Other & 7 & 2 \\
\hline
\end{tabular}

\begin{tabular}{|lcc|} 
Item 6 & & \\
\hline Self & 2 & 0 \\
& 1 & $\mid$ \\
Other & 63 & 50 \\
\hline
\end{tabular}

Item 9
\begin{tabular}{|lcc|}
\hline Self & 98 & 100 \\
& $\mid$ & $\mid$ \\
Other & 37 & 50 \\
\hline
\end{tabular}

\begin{tabular}{|lcc|} 
Item 10 & & \\
\hline Self & 15 & 7 \\
& $\mid$ & $\mid$ \\
Other & 85 & 75 \\
\hline
\end{tabular}

Item 13
\begin{tabular}{|lcc|}
\hline Self & 93 & 85 \\
& $\mid$ & $\mid$ \\
Other & 75 & 85 \\
\hline
\end{tabular}

\begin{tabular}{|lcc|} 
Item 14 & & \\
\hline Self & 50 & 37 \\
& $\mid$ & $\mid$ \\
Other & 100 & 98 \\
\hline
\end{tabular}

Item 17
\begin{tabular}{|lcc|}
\hline Self & 25 & 15 \\
& I & $\mid$ \\
Other & 93 & 85 \\
\hline
\end{tabular}

\begin{tabular}{|lcc|} 
Item $\mathbf{1 8}$ & & \\
\hline Self & 37 & 25 \\
& $\mid$ & $\mid$ \\
Other & 98 & 93 \\
\hline
\end{tabular}

\section{Item 21}

\begin{tabular}{|lcc|}
\hline Self & 75 & 63 \\
& I & I \\
Other & 93 & 98 \\
\hline
\end{tabular}

\section{Item 22}

\begin{tabular}{|lcc|}
\hline Self & 63 & 50 \\
& $\mid$ & $\mid$ \\
Other & 98 & 100 \\
\hline
\end{tabular}

Item 3

\begin{tabular}{|lcc|}
\hline Self & 85 & 75 \\
& $\mid$ & $\mid$ \\
Other & 85 & 93 \\
\hline
\end{tabular}

\section{Item 7}

\begin{tabular}{lll}
\hline Self & 7 & 15
\end{tabular}

Other $\quad 25 \quad 15$

Item 11

\begin{tabular}{|lll|}
\hline Self & 93 & 98
\end{tabular} $\begin{array}{lll} & 1 & \mid \\ \text { Other } & 25 & 37\end{array}$

Item 15

Self $50 \quad 63$

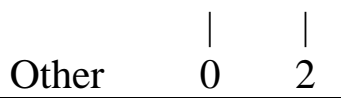

Item 19

\begin{tabular}{lll}
\hline Self & $100 \quad 98$
\end{tabular}

$\begin{array}{lcc} & & \\ \text { Other } & 50 & 63\end{array}$

Item 23

Self $\quad 75 \quad 85$

$\begin{array}{lll} & \mid & \mid \\ \text { Other } & 7 & 15\end{array}$ 


\section{Slider Task}

\section{Example}

\begin{tabular}{|lccccccccc|}
\hline Self & 30 & 35 & 40 & 45 & 50 & 55 & 60 & 65 & 70 \\
& 1 & $\mid$ & $\mid$ & $\mid$ & $\mid$ & $\mid$ & $\mid$ & $\mid$ & $\mid$ \\
Other & 80 & 70 & 60 & 50 & 40 & 30 & 20 & 10 & 0 \\
\hline
\end{tabular}

\section{Item 1}

\begin{tabular}{|lccccccccc|}
\hline Self & 85 & 85 & 85 & 85 & 85 & 85 & 85 & 85 & 85 \\
& $\mid$ & $\mid$ & $\mid$ & $\mid$ & $\mid$ & $\mid$ & $\mid$ & $\mid$ & $\mid$ \\
Other & 85 & 76 & 68 & 59 & 50 & 41 & 33 & 24 & 15 \\
\hline
\end{tabular}

Item 2

\begin{tabular}{|lccccccccc|}
\hline Self & 85 & 87 & 89 & 91 & 93 & 94 & 96 & 98 & 100 \\
& 1 & $\mid$ & $\mid$ & $\mid$ & $\mid$ & $\mid$ & $\mid$ & $\mid$ & $\mid$ \\
Other & 15 & 19 & 24 & 28 & 33 & 37 & 41 & 46 & 50 \\
\hline
\end{tabular}

Item 3

\begin{tabular}{|lccccccccc|}
\hline Self & 50 & 54 & 59 & 63 & 68 & 72 & 76 & 81 & 85 \\
& $\mid$ & $\mid$ & $\mid$ & $\mid$ & $\mid$ & $\mid$ & $\mid$ & $\mid$ & $\mid$ \\
Other & 100 & 98 & 96 & 94 & 93 & 91 & 89 & 87 & 85 \\
\hline
\end{tabular}

\section{Item 4}

\begin{tabular}{|lccccccccc|}
\hline Self & 50 & 54 & 59 & 63 & 68 & 72 & 76 & 81 & 85 \\
& 1 & $\mid$ & $\mid$ & $\mid$ & $\mid$ & $\mid$ & $\mid$ & $\mid$ & $\mid$ \\
Other & 100 & 89 & 79 & 68 & 58 & 47 & 36 & 26 & 15 \\
\hline
\end{tabular}

Item 5

\begin{tabular}{|lccccccccc|}
\hline Self & 100 & 94 & 88 & 81 & 75 & 69 & 63 & 56 & 50 \\
& $\mid$ & $\mid$ & $\mid$ & $\mid$ & $\mid$ & $\mid$ & $\mid$ & $\mid$ & $\mid$ \\
Other & 50 & 56 & 63 & 69 & 75 & 81 & 88 & 94 & 100 \\
\hline
\end{tabular}

Item 6

\begin{tabular}{|lccccccccc|}
\hline Self & 100 & 98 & 96 & 94 & 93 & 91 & 89 & 87 & 85 \\
& $\mid$ & $\mid$ & $\mid$ & $\mid$ & $\mid$ & $\mid$ & $\mid$ & $\mid$ & $\mid$ \\
Other & 50 & 54 & 59 & 63 & 68 & 72 & 76 & 81 & 85 \\
\hline
\end{tabular}




\title{
Supplementary Information 2 - General Instructions
}

\author{
Note: Instructions are translated from German.
}

\section{Experiment 1}

\section{Welcome!}

Thank you very much for participating in our study. You will receive a fixed payoff of 5 Euro or .75 hours of course credit. Additionally, you will work on two tasks for which you will receive points depending on your own decisions and those of other participants. These points will be converted into money at the end of the study and paid to you. The conversion rate from points to Euro is 100 points $=1$ Euro.

Your task in this part of the study is to determine how you want to divide points between yourself and another, randomly selected and anonymous participant. All your decisions are completely confidential. Each time you make a decision, you will indicate a distribution of points that you prefer most.

You will make a total of 24 decisions between two possible distributions each. Based on these decisions, you and the other person will receive points.

These points are located behind fields that are displayed on the screen. To find out how many points you or the other person receive, move your computer mouse over the corresponding fields. As long as the mouse pointer is over a field, you will see the corresponding number of points. This principle will be illustrated by an example. When you have decided on a distribution, click on the corresponding button.

Once all decisions have been made, we will randomly match you with two other participants in the room and assume the following roles:

\section{Your role as SENDER:}

You act as a sender with regard one of the participants. One of your own decisions will be randomly drawn. You then receive the points that you have assigned to yourself, while the other participant receives the points that you have assigned to him.

Your role as RECIPIENT:

You act as recipient with regard to the second participant. One decision of the other participant will be randomly drawn. You then receive the points assigned to you by the other participant, while the other participant receives the points assigned to himself.

\section{(Ring Task starts)}

The first task has now been completed. We will inform you about your points at the end of the study. The study will continue in a few seconds. 
Your task in the second part of the study is to determine again how you want to divide points between yourself and another, randomly selected and anonymous participant. Each time you make a decision, you will give the distribution of points that you prefer most. All your decisions are completely confidential.

In the following task, you will make a total of 15 decisions between nine possible distributions. Based on these decisions, you and the other person will receive points.

As with the first task, these points are located behind fields that are displayed on the screen. To find out how many points you or the other person receive, move the computer mouse over the corresponding fields. As long as the mouse pointer is over a field, you will see the corresponding number of points. This principle will be illustrated by an example. When you have decided on a distribution, click on the corresponding button.

Once all decisions have been made, we will randomly match you with two other participants in the room. These are other participants than those in the first task, but you will assume the same two roles:

Your role as SENDER:

You act as a sender with regard one of the participants. For this one of your own decisions will be randomly drawn. You then receive the points that you have assigned to yourself, while the other participant receives the points that you have assigned to him.

Your role as RECIPIENT:

You act as recipient with regard to the second participant. For this purpose, a decision of the other participant will be randomly drawn0. You then receive the points assigned to you by the other participant, while the other participant receives the points assigned to himself.

Your decisions in this task do not affect the points you receive for the first task.

(Slider Task starts)

\section{Experiment 2}

\section{Welcome!}

Thank you very much for participating in our study. You will receive a fixed payoff of 5 Euro or .75 hours of course credit. Additionally, you will work on two tasks for which you will receive points depending on your own decisions and those of other participants. These points will be converted into money at the end of the study and paid to you. The conversion rate from points to Euro is 100 points $=1$ Euro.

Your task in this part of the study is to determine how you want to divide points between yourself and another, randomly selected and anonymous participant. All your decisions are completely confidential. Each time you make a decision, you will indicate a distribution of points that you prefer the most. 
You will make a total of 24 decisions between two possible distributions each. Based on these decisions, you and the other person will receive points.

These points are located behind fields that are displayed on the screen. To find out how many points you or the other person receive, move your computer mouse over the corresponding fields. As long as the mouse pointer is over a field, you will see the corresponding number of points. This principle will be illustrated by an example. When you have decided on a distribution, click on the corresponding button.

Once all decisions have been made, we will randomly match you with two other participants in the room and assume the following roles:

\section{Your role as SENDER:}

You act as a sender with regard one of the participants. For this one of your own decisions will be randomly drawn. You then receive the points that you have assigned to yourself, while the other participant receives the points that you have assigned to him.

Your role as RECIPIENT:

You act as recipient with regard to the second participant. For this purpose, a decision of the other participant will be randomly drawn0. You then receive the points assigned to you by the other participant, while the other participant receives the points assigned to himself.

\section{(Ring Task starts)}

The first task has now been completed. We will inform you about your points at the end of the study. The study will continue in a few seconds.

Your task in the second part of the study is to determine again how you want to divide points between yourself and another, randomly selected and anonymous participant. Each time you make a decision, you will give the distribution of points that you prefer most. All your decisions are completely confidential.

In the following task, you will make a total of 15 decisions between nine possible distributions. Based on these decisions, you and the other person will receive points.

As with the first task, these points are located behind fields that are displayed on the screen. To find out how many points you or the other person receive, move the computer mouse over the corresponding fields. As long as the mouse pointer is over a field, you will see the corresponding number of points. This principle will be illustrated by an example. When you have decided on a distribution, click on the corresponding button.

Once all decisions have been made, we will randomly match you with two other participants in the room. These are other participants than those in the first task, but you will assume the same two roles:

Your role as SENDER: 
You act as a sender with regard one of the participants. For this one of your own decisions will be randomly drawn. You then receive the points that you have assigned to yourself, while the other participant receives the points that you have assigned to him.

Your role as RECIPIENT:

You act as recipient with regard to the second participant. For this purpose, a decision of the other participant will be randomly drawn0. You then receive the points assigned to you by the other participant, while the other participant receives the points assigned to himself.

Your decisions in this task do not affect the points you receive for the first task.

(Slider Task starts) 


\section{Supplementary Information 3 - Demonstration Instructions for the SVO Tasks}

Instructions are translated from German. These instructions were consecutively presented during a demonstration trial with a randomly selected, predefined choice (see example for the Slider

Task). Text in the Slider Task is given in square brackets after the text in the Ring Task.
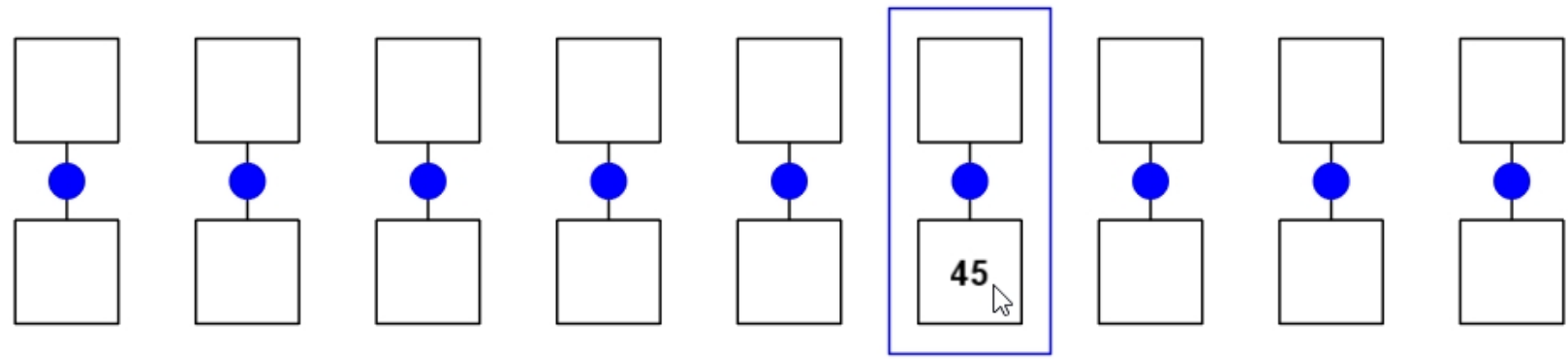

\section{Example}

Before the actual task, an example will show you which decisions you make and how you can find information about the allocations.

click on "continue"

You always choose one of two [nine] possible distributions. Your decision determines how many points you assign to yourself and the other person.

click on "continue"

You can obtain information about the distributions by moving the mouse over the corresponding boxes. During this time, you can see the resulting points.

click on "continue"

Now move the mouse over the boxes belonging to the distribution marked with the blue frame. In this distribution you receive 45 points and the other person receives 50 points.

click on "continue"

Once you have decided on a distribution, you can select it by clicking on the blue dot between the two corresponding boxes.

click on "continue"

To complete the example and start the task, select the distribution marked with the blue frame. To do this, click on the corresponding blue dot.

click on the correct distribution 


\title{
Supplementary Information 4 - Intuitive and Reflective Planning Instructions
}

\author{
Instructions are translated from German. Text that varied between the intuitive (I) and the \\ reflective $(\mathrm{R})$ conditions given in square brackets.
}

\section{Preparation for the decision}

In the second part of the study, you will again decide how you want to distribute points between yourself and another person. Think about your wishes for the upcoming decisions. What is your most important wish for the upcoming decisions? What exactly is your wish about? Please write down this wish now:

\section{The best outcome}

What is the one best outcome of realizing your wish? Please answer in one or two keywords. The best outcome is:

Now, imagine your one best outcome. Imagine the events and experiences that you associate with this outcome. Take as much time as you need. Allow these events and experiences to play out and write them down. If you need more space, please continue writing overleaf.

Sometimes things do not work out as we wish. Often, [I: pondering at length, R: acting in a hasty way] stands in the way of realizing a wish. [I: One agonizes over all aspects and hesitates, without reaching a satisfactory solution, R: One rushes through a couple of aspects and acts hastily, not reaching a satisfactory solution]. [I: Pondering at length, R: Acting in a hasty way] may hinder one from realizing a wish. Researchers assume that people who [I: ponder at length, $\mathrm{R}$ : act in a hasty way] may actually make worse decisions. The main obstacle for the upcoming decisions is thus [I: pondering at length, R: acting in a hasty way].

Now imagine that you [I: ponder at length about, R: act in a hasty way when making] the upcoming decisions. Imagine the events and experiences that you associate with [I: pondering at length about, R: acting in a hasty way when making] the upcoming decisions. Take as much time as you need. Allow these events and experiences to play out and write them down. If you need more space, please continue writing overleaf.

To realize your wish, you should thus [I: listen to your guts, R: use your brain]. Research has demonstrated that making if-then plans helps you with this. Therefore, make the following if-then plan: When I start [I: pondering at length, R: acting in a hasty way], then I will tell myself: [I: Listen to your guts, R: Use your brain]! Picture this plan in your mind's eye and memorize it. Say the if-then plan three times to yourself. When you have learned the plan by heart, proceed to the next page.

Please write down your plan: When , then I will tell myself: ! 


\section{Supplementary Information 5 - Final Questionnaire in Experiment 2}

Instructions are translated from German. Text that varied between the intuitive (I) and the reflective $(\mathrm{R})$ conditions is given in square brackets. Items marked with $\mathrm{a}, \mathrm{b}, \mathrm{c}$, and $\mathrm{d}$ represent comprehension check, plan commitment, general plan relevance, and specific plan relevance items, respectively.

In the following questionnaire we ask you to provide some demographic information. This information will be treated confidentially and will only be used for the analysis of this study.

- What year were you born?

- Which gender do you have?

- What is your mother tongue?

- Which major do you study?

- Which minor do you study?

- Which semester are you in?

- How many courses with mathematical content have you already attended?

- How many courses with statistical content have you already attended?

This questionnaire contains a number of statements that refer to the plan from the instructions: If I start acting in a hasty way, then I will tell myself: Use your brain! [If I start pondering at length, then I will tell myself: Listen to your guts!] Read each statement and use the scale to indicate the extent to which each statement applies to you. There are seven gradations available $(1$ = not applicable, $7=$ completely applicable $)$.

- It was difficult to take this plan seriously. ${ }^{\mathrm{b}}$

- Frankly, I didn't care if I acted upon the plan or not. ${ }^{b}$

- I was strongly committed to the plan. ${ }^{\mathrm{b}}$

- It didn't take much for me to abandon the plan. ${ }^{\mathrm{b}}$

This questionnaire contains statements that relate to the effect of the preparatory exercise on your decisions in the second task. Read each statement and use the scale to indicate the extent to which each statement applies to you. There are seven gradations available $(1=$ not applicable, 7 = fully applicable).

I felt instructed...

- not to think about my decision. ${ }^{\text {a }}$

- to make unfavorable decisions. ${ }^{\text {a }}$

- to make my decisions slowly. ${ }^{\mathrm{a}}$

- to think thoroughly about my decisions. ${ }^{\text {a }}$

- to make my decisions quickly. ${ }^{\text {a }}$

- to make particularly good decisions. ${ }^{\mathrm{a}}$ 
The following questions are about how you make decisions in general. Read each statement and use the scale to indicate the extent to which each statement applies to you. There are seven gradations available $(1=$ not applicable, $7=$ fully applicable $)$.

In general,

- I [I: ponder at length, R: act hastily] when making decisions. ${ }^{\mathrm{c}}$

- [I: pondering at length, R: acting hastily] when making decisions prevents me from attaining my goals. ${ }^{\mathrm{c}}$

The following questions are about how you made decisions in the second task of this study.

In the second task of this study,

- I [I: pondered at length, R: acted hastily] when making decisions. ${ }^{\mathrm{d}}$

- [I: pondering at length, R: acting hastily] when making decisions prevented me from attaining my goals. ${ }^{\mathrm{d}}$

- I perceived [I: pondering at length, R: acting hastily] when making decisions as a possible obstacle to attaining my goals. ${ }^{\mathrm{d}}$ 


\section{Supplementary Information 6: Additional Graphs}

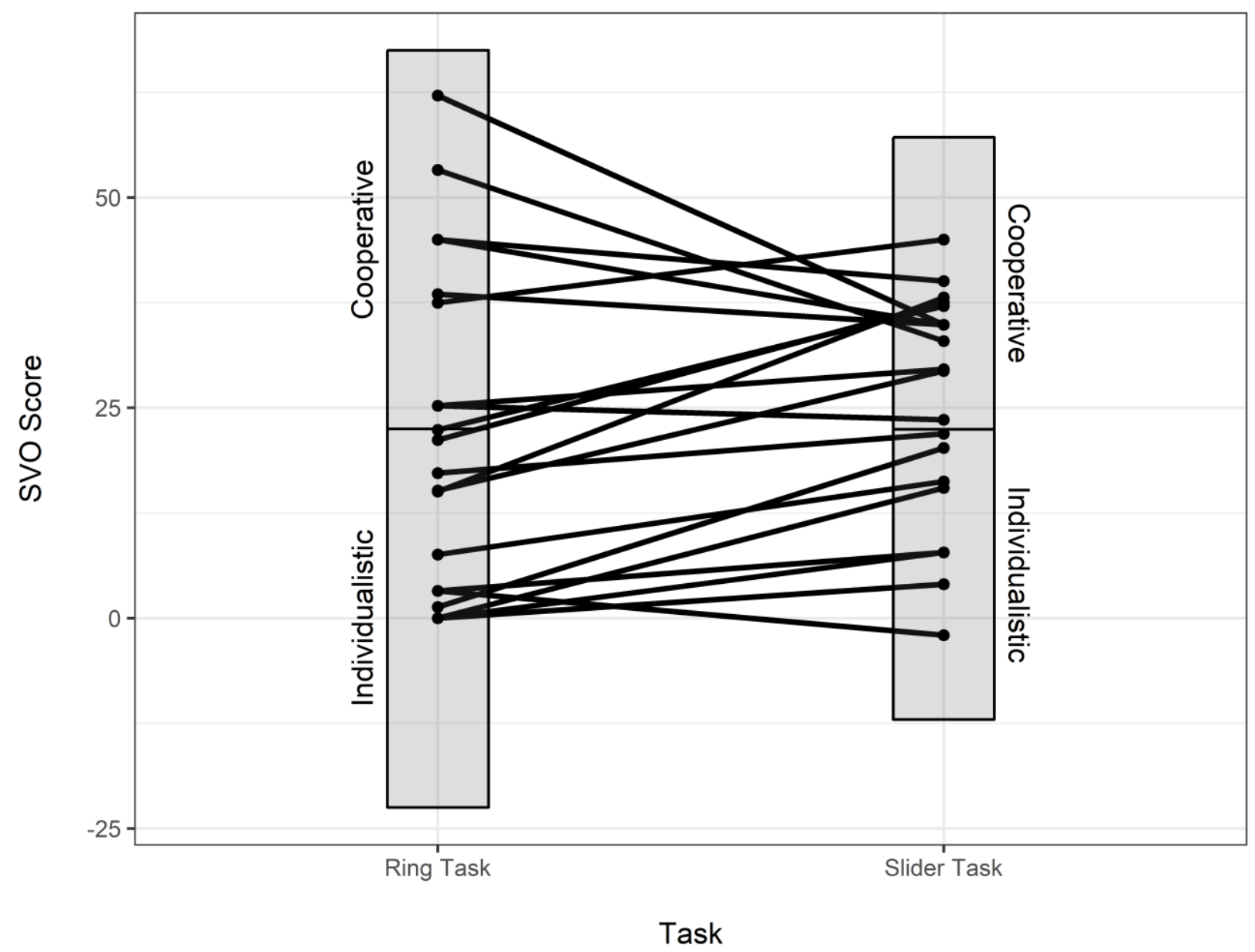

Figure S1. Mapping between continuous SVO scores and nominal classifications between the

Ring Task and the Slider Task in Experiment 1. 


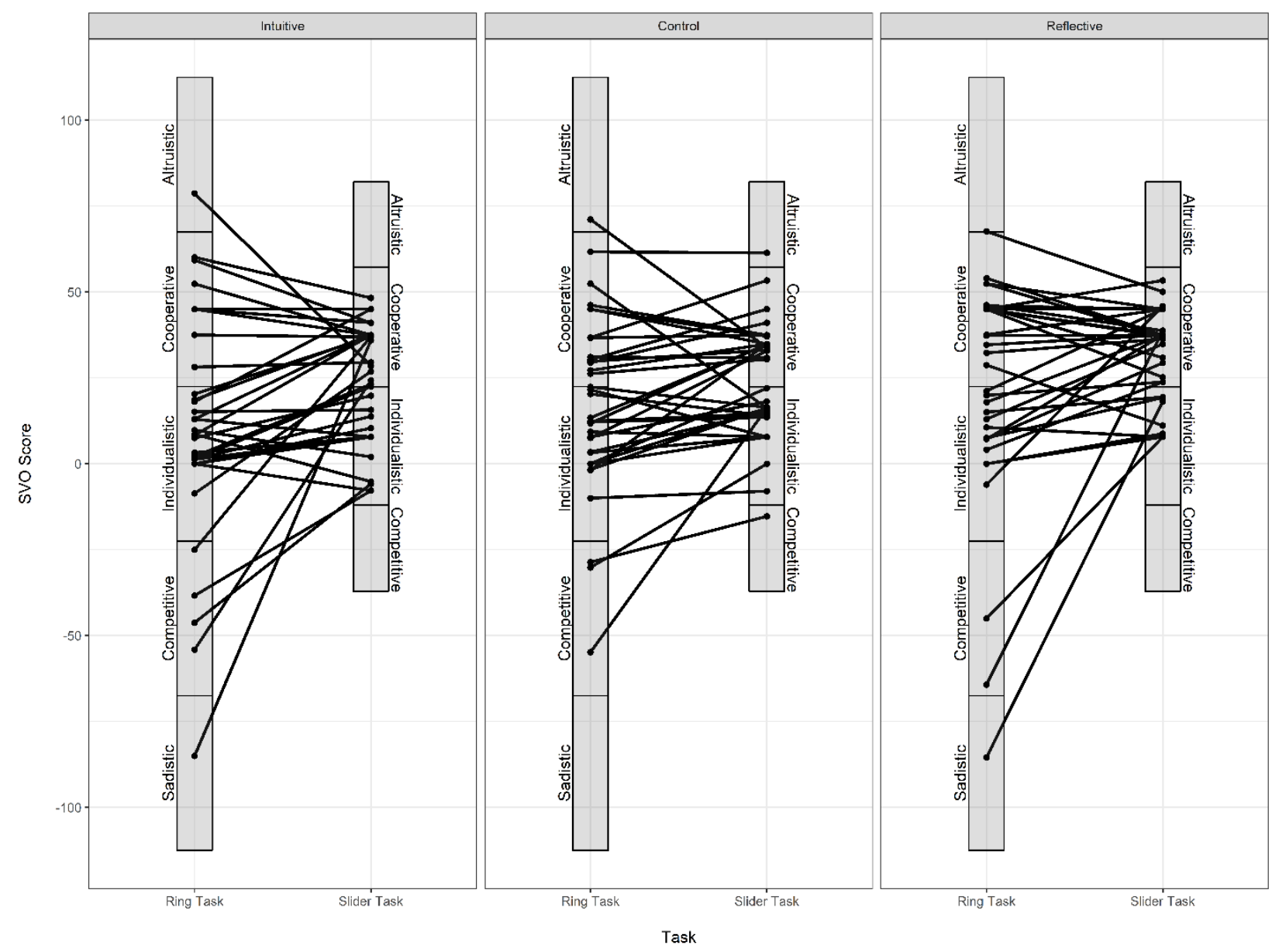

Figure S2. Mapping between continuous SVO scores and nominal classifications between the Ring Task and the Slider Task in Experiment 2 separately for each condition. 